\title{
Optimized Sizing, Selection, and Economic Analysis of Battery Energy Storage for Grid-Connected Wind-PV Hybrid System
}

\author{
Hina Fathima and K. Palanisamy \\ School of Electrical Engineering, VIT University, Vellore Campus, Vellore District, Tamil Nadu 632 014, India \\ Correspondence should be addressed to Hina Fathima; hina.fathima49@gmail.com
}

Received 21 September 2015; Revised 13 November 2015; Accepted 22 November 2015

Academic Editor: Elio Chiodo

Copyright ( $) 2015$ H. Fathima and K. Palanisamy. This is an open access article distributed under the Creative Commons Attribution License, which permits unrestricted use, distribution, and reproduction in any medium, provided the original work is properly cited.

\begin{abstract}
Energy storages are emerging as a predominant sector for renewable energy applications. This paper focuses on a feasibility study to integrate battery energy storage with a hybrid wind-solar grid-connected power system to effectively dispatch wind power by incorporating peak shaving and ramp rate limiting. The sizing methodology is optimized using bat optimization algorithm to minimize the cost of investment and losses incurred by the system in form of load shedding and wind curtailment. The integrated system is then tested with an efficient battery management strategy which prevents overcharging/discharging of the battery. In the study, five major types of battery systems are considered and analyzed. They are evaluated and compared based on technoeconomic and environmental metrics as per Indian power market scenario. Technoeconomic analysis of the battery is validated by simulations, on a proposed wind-photovoltaic system in a wind site in Southern India. Environmental analysis is performed by evaluating the avoided cost of emissions.
\end{abstract}

\section{Introduction}

India has been suffering from power shortages for three decades. Government organizations all over the world are vowing for a cleaner energy policy and promoting renewable power to combat growing power demands. According to the Renewables Global Status Report (2015) [1] 19.1\% of world energy consumption in 2013 was met by renewable energy alone. Hybrid Renewable Energy Systems (HRES) are emerging as the key solutions to overcome the unpredictability and variability in renewables by combining two or more power sources, enabling the system to be reliable and cost-effective. But many problems arise in their planning, operation, and scheduling. Energy storages are needed to balance load, bridge power gap, and improve power quality. Initiation of energy storage demonstration projects by the MNRE, Government of India in August, 2015 [2], has raised hopes to revolutionize the Indian energy storage market. Grid level storages for implementing renewable energy integration, experimenting with energy arbitrage, and supporting ancillary services need to be explored under Indian power markets.
Battery Energy Storage Systems (BESS) are the most mature storage technology and they offer a wide range of characteristics for varied applications. BESS comprise multiple electrochemical cells connected in arrays to deliver electricity at desired capacity and potential. As the energy is stored in form of electrochemical energy, the entire bulk of the battery is prone to chemical reactions. Hence, they require high maintenance which presented a major setback. Developing technology and material science enabled design of materials which allow this ingress of reactions up to several thousand times, thus evolving rechargeable batteries with reduced maintenance. Recent times have seen tremendous advancements in BESS with the emergence of advanced rechargeable valve-regulated lead-acid batteries, sodium batteries, lithium batteries, and flow batteries. Governments and research agencies are making large scale investments implementing batteries for both grid and transport applications. There are yet many challenges to be addressed for safe integration, operation, and disposal of batteries.

Many studies could be found in the literature on inclusion of energy storages with HRES. Zhao et al. [3] presented a review of planning, operating, and controlling studies in 
wind and energy storage integrated systems. Poullikkas [4] gave a detailed economic overview of battery storage systems for large-scale electricity storage. Maleki and Askarzadeh [5] optimally sized a PV-Wind-Diesel-Battery hybrid system with discrete harmony search algorithm. Further expansion of the HRES with a fuel cell hydrogen storage system [6] was attempted and the results proved the batteries to be a better investment option. Prodromidis and Coutelieris [7] simulated and analyzed nine types of HRES with storages like batteries and flywheels based on the net present costs of systems. These results also proved the batteries to be a standard choice for HRES integration. These studies were conducted on standalone systems and the authors evaluated the economic costs of BESS. However, the current study deals with grid-connected systems and is scheduled to match a predetermined power dispatch, failing of which leads to load shedding and losses. Integrating BESS with renewables necessitates optimizing battery capacity so as to minimize investment and operation costs and increase battery lifetime. A deep analysis and understanding of the characteristics of the different batteries available is important to justify selection of a battery for a particular application. Various types of BESS and their applications in wind systems were explored prior to this study and a detailed overview of it can be seen in [8]. Inverters of flooded lead-acid batteries have seen widespread domestic installations in India. Keeping in view India's geographical, economic, and energy scenarios, five batteries have been identified for analysis in this paper and will be explained in the next sections.

Gitizadeh and Fakharzadegan [9] proposed sizing of BESS for a grid-connected PV system using the General Algebraic Modeling System (GAMS) to minimize the cost of the battery. Bahmani-Firouzi and Azizipanah-Abarghooee [10] implemented an improved bat algorithm to evaluate the size of a BESS with the minimum operation and maintenance costs. Li et al. [11] developed a dispatch strategy to maximize the lifetime of the battery by ensuring maximum chargedischarge in each cycle. However, scheduling dispatch based on State of Charge (SOC) of storages may not be appropriate while dispatching wind power with the grid. Johnson et al. [12] explored an online scheduling problem using batteries to harvest peak shaving with optimization algorithms. Above studies aim at only optimizing the battery costs but do not consider the expense of losses, which may increase if the battery size selected is too small. In an effort to balance the investment cost of battery and losses, a multiobjective optimization function to reduce investment costs and losses is presented here.

Dicorato et al. [13] discussed the effect of battery storage sizing on the planning and operation of the hybrid system. The results proved that a higher rating of BESS can aid in higher renewable penetration and gain more advantages by controlling power bids. But, if the nominal size of the BESS exceeds that of the system it may cause more expenses and design issues. Brekken et al. [14] explored the effect of power flow control strategy on sizing of energy storage by imposing fuzzy and artificial neural network control strategies. Ma et al. [15] published a feasibility study for windPV-battery HRES using HOMER and portrayed the effects of individual system configurations on the HRES performance. These studies provide a benchmark for the current study in terms of sizing results for the battery system. Economic analysis and feasibility studies have been attempted in many applications for power systems from a long time [16]. In [17], the authors exhibited an excellent cost analysis for solar PV systems based on payback periods. A study by Kaabeche and Ibtiouen [18] proposed an optimal configuration of a wind-PV HRES considering economic metrics including net present costs, cost of energy, and energy deficits. DufoLópez [19] concluded that, for introducing storage to AC grids, an adequate TOU tariff and drop in battery costs are crucial to ensure profitability. The presented case study explores the economic aspects of investing in energy storages under Indian markets which are governed by fixed tariff rates. Also, many system metrics including payback periods and net present costs are explored for battery storages to investigate the investment feasibility. Additionally, this paper also evaluates an avoided cost of emissions to point out the significance of investing in emission free storage technology.

This paper presents a feasibility study of integrating battery storage to a Wind-PV HRES. The HRES is scheduled to meet a power dispatch curve which implements peak shaving and ramp rate limiting to avoid power surges in the grid. An optimized sizing methodology for evaluating the battery capacity and cost which successfully satisfies all power constraints is proposed. The sizing methodology is then validated with a $275 \mathrm{~kW}$ grid-connected wind-PV hybrid renewable system and tested with five different types of batteries. The performance of each battery is simulated and comparisons are made based on technoeconomic metrics. Simulations are carried out in MATLAB and all evaluations are done based on Indian power market scenario. Hence, the aim of peak shaving is to improve power delivery and not energy arbitrage. A further exploration of profits gained by avoiding emissions is also included to emphasize the environmental benefits of adopting battery storage in the HRES. The paper is structured as follows. Section 2 entails modeling of system components and scheduling of power dispatch. A brief summary of types of battery systems and the sizing methodology are explained in detail in Section 3. The performance and economic analysis of different batteries are entailed in Section 4. The last section summarizes the simulation results and comparative analyses of the battery systems.

\section{Modeling of System Components}

The Hybrid Renewable Energy System shown in Figure 1 consists of a $200 \mathrm{~kW}$ wind turbine MICON M450-200 which has an asynchronous machine operating at $400 \mathrm{~V}$ whose specifications can be seen at [20]. A $75 \mathrm{~kW}$ PV panel is connected to the HRES through a rectifier to produce alternating current. It is assumed that the proposed windPV system acts as a power injection system to the power grid and lacks the features to exert any kind of power quality control on the power generated. The power generated by the wind turbine is directly pumped via $\mathrm{AC}$ grid to the distribution station. The power from the solar panels is fed to 


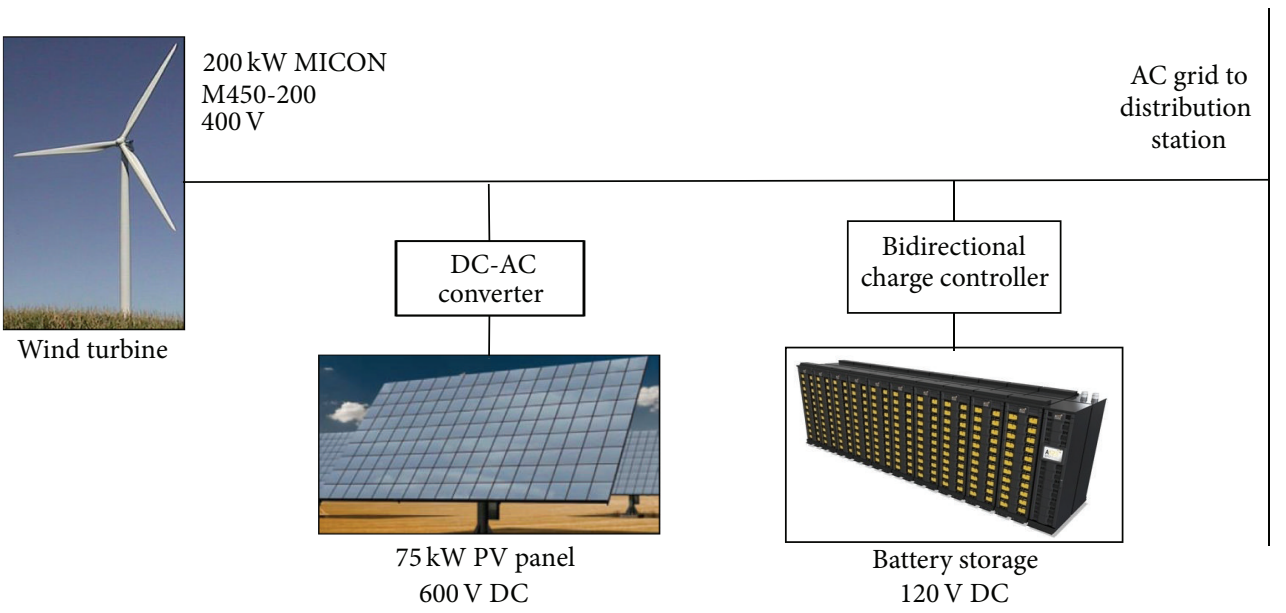

Figure 1: Schematic diagram of Hybrid Renewable Energy System.

the grid via DC-AC converter. A bidirectional charge controller charges/discharges the battery and takes care of the AC-DC conversion and voltage boosting. The unpredictable nature of renewable sources makes the system incapable of meeting the power dispatch standards of the load dispatch centres. Also, at times of high wind availability the turbines are forced to shut down due to lack of power evacuation facilities. Integrating battery with the HRES will help to store the spilled energy and deliver it at times of peak power demands thus improving the system reliability. The methodology used for sizing and analysis is shown in Figure 2.

Initially, power generated by the HRES is calculated by modeling the system components. A simple power dispatch strategy is evaluated to remove all intermittences in the generated power. It also enables storage of energy at low demand periods and delivering it at times of peak load, that is, peak shaving and ramp rate limiting to avoid sudden surges entering the grid. The battery capacity needed to meet this power dispatch is estimated and optimized using bat algorithm. The optimized results are tested by operating five different types of batteries with the HRES. A simple energy management strategy is also included to avoid over charging/discharging of the battery. From the results obtained, analysis and comparisons are made to identify the most suitable battery for the HRES.

2.1. Wind Turbine Modeling. The power generated in a wind turbine is evaluated using (1) [21]. The turbine starts generating power at wind speeds greater than cut-in speed $v_{\mathrm{ci}}$. $C_{p}(\lambda, \beta)$ is the power coefficient of the wind turbine which is a function of pitch angle $\beta$ and tip-speed ratio $\lambda$ and is plotted in Figure 3. The turbine continues to produce rated power after attaining rated speed and at reaching cut-out speeeds the turbine is stalled. The power curve thus obtained is shown in Figure 4. Consider

$$
P_{w}(v)= \begin{cases}0, & v \leq v_{\mathrm{ci}} \text { or } v \geq v_{\mathrm{co}} \\ 0.5 \rho A C_{p}(\lambda, \beta) v^{3}, & v_{\mathrm{ci}} \leq v \leq v_{r} \\ P_{\text {rated-wt }}, & v_{r} \leq v \leq v_{\mathrm{co}} .\end{cases}
$$

2.2. PV System. A silicon PV module output depends on many variables including the type of material, temperature, and solar radiance incident on the surface of the module. Its output can be expressed as [22]

$$
P_{\mathrm{pv}}=Y_{\mathrm{pv}} f_{\mathrm{pv}} \frac{G_{c}}{G_{\mathrm{STC}}}\left[1+\alpha\left(T_{c}-T_{\mathrm{STC}}\right)\right] .
$$

$G_{\text {STC }}$ and $T_{\text {STC }}$ are taken to be $1000 \mathrm{~W} / \mathrm{m}^{2}$ and $25^{\circ} \mathrm{C}$, respectively. $\alpha$ and $f_{\mathrm{pv}}$ are considered as $0.4 \%$ and $97 \%$, respectively.

2.3. Power Dispatch Curve. Renewable power systems cannot be considered as a dispatchable generation due to their uncontrolled and intermittent nature. On the contrary, load dispatch centers demand a 15-minute time block at the least for scheduling and dispatch of power to the grid [23]. However, energy storages can be employed in making this intermittent power dispatchable. In this study, power dispatch is scheduled for every 30 minutes (computation for two time blocks) and any mismatch of generated power in this time interval is nullified by the battery storage. Thus, the power output from the hybrid system will be constant for $30 \mathrm{~min}$. Let $P_{\text {gen }}$ be the total power generated by the hybrid system given as below. Here the efficiencies take into account the efficiency of the power generating system and its connected power converters. One has

$$
P_{\text {gen }}(t)=\left(P_{w}(t) \times \eta_{\mathrm{wt}}\right)+\left(P_{\mathrm{pv}}(t) \times \eta_{\mathrm{pv}}\right) .
$$

The power dispatch curve $P_{\text {dem }}(t)$ includes peak shaving and ramp rate limiting. The dispatch curve is obtained by following an average of $P_{\text {gen }}(t)$ generated per day, denoted by $P G_{\mathrm{av}}(i)$, where " $i$ " is the day of month. At times of offpeak demand, some of the energy generated is stored in batteries and the rest is delivered. And during peak load, this saved energy is dispatched as shown in Table 1. This is to ensure optimum usage of the energy storage device while implementing peak shaving. Whenever $P_{\text {gen }}(t)$ experiences surges due to wind gusts, it may affect the grid stability, 


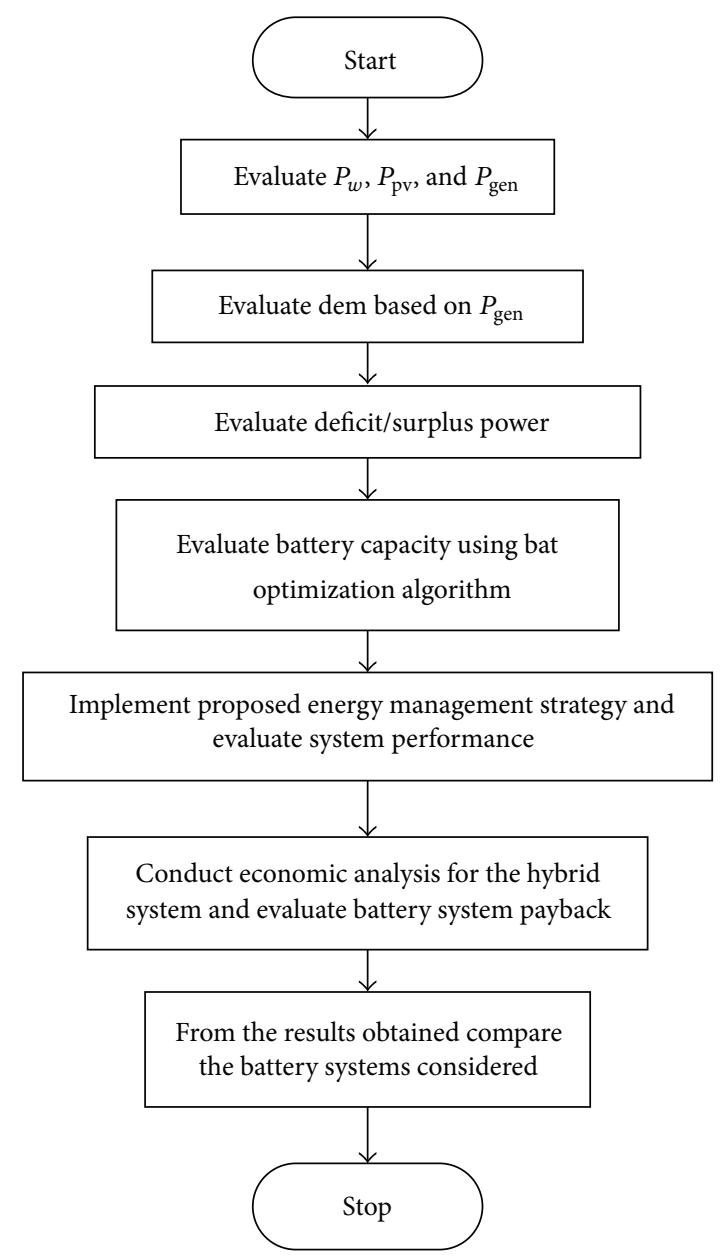

Figure 2: Energy storage sizing methodology.

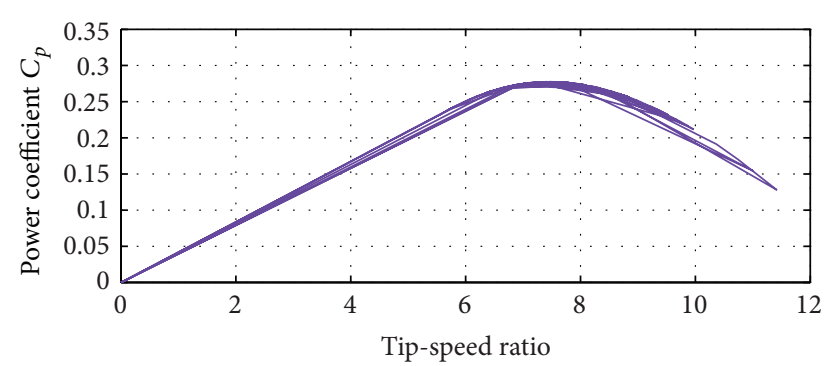

Figure 3: $C_{p}$ curve.

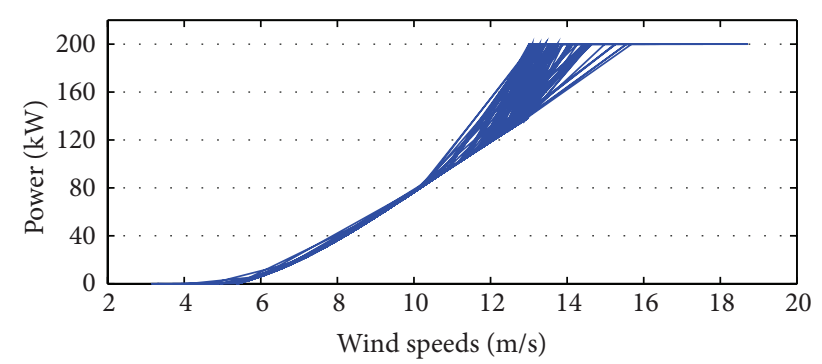

FIgURE 4: Wind turbine power curve.
TABLE 1: Dispatch curve evaluation.

\begin{tabular}{lcc}
\hline Hour of day & Demand period & Dispatch $\left(P_{\text {dem }}(t)\right)$ \\
\hline 00.00 to 07.00 & Morning off-peak & $P_{\text {gen }}(t) / 2$ \\
07.00 to 11.00 & Morning peak & $P G_{\text {av }}(i)+\left(P_{\text {gen }}(t) / 2\right)$ \\
11.00 to 19.00 & Midday off-peak & $\left(P_{\text {gen }}(t)+P G_{\text {av }}(i)\right) / 2$ \\
19.00 to 23.00 & Evening peak & $P G_{\text {av }}(i)+\left(P_{\text {gen }}(t) / 2\right)$ \\
23.00 to 0.00 & Evening off-peak & $P_{\text {gen }}(t) / 2$ \\
\hline
\end{tabular}

thereby necessitating ramp rate control. In case of any unscheduled power surge/fall (occurring at times other than scheduled ramp changes of load shifting from off-peak to peak and vice versa) of more than $\pm 5 \%$ of rated power, the excess/deficit power is directed to the battery. Figure 5 shows the power dispatch curve $P_{\mathrm{dem}}(t)$ plotted against the $P_{\text {gen }}(t)$ curve.

\section{Optimal Sizing of Energy Storage}

3.1. Selection of Battery Energy Storage Systems (BESS). BESS are made of multiple electrochemical cells connected in series or stacks to get the desired voltage and capacity, 
TAble 2: Properties of batteries $[8,24,25]$.

\begin{tabular}{|c|c|c|c|c|c|c|c|c|c|}
\hline Technology & $\begin{array}{l}\text { Capital cost } \\
\text { in } \$ / \mathrm{kWh}\end{array}$ & $\begin{array}{l}\text { Discharge } \\
\text { time }\end{array}$ & $\begin{array}{l}\text { Energy } \\
\text { rating } \\
(\mathrm{MWh})\end{array}$ & $\begin{array}{c}\text { Specific } \\
\text { energy } \\
(\mathrm{Wh} / \mathrm{kg})\end{array}$ & $\begin{array}{c}\text { Cycling } \\
\text { capability, @ } \\
\text { \% DoD }\end{array}$ & Life (yrs) & $\begin{array}{c}\text { Energy } \eta \\
(\%)\end{array}$ & $\begin{array}{c}\text { Self- } \\
\text { discharge } \\
(\%)\end{array}$ & $\begin{array}{c}\text { Operating } \\
\text { temperature } \\
\text { in }{ }^{\circ} \mathrm{C} \\
\end{array}$ \\
\hline Pb-acid & 50-150 & Sec.-hrs & $0.001-40$ & $35-50$ & $\begin{array}{l}500-2000 \\
\text { @ } 70\end{array}$ & 5-15 & $70-80$ & $<0.2$ & -5 to 40 \\
\hline $\mathrm{Na}-\mathrm{S}$ & $200-600$ & Sec.-hrs & $0.4-244.8$ & $100-175$ & $2500 @ 100$ & $10-20$ & $75-89$ & No & 325 \\
\hline $\mathrm{Ni}-\mathrm{Cd}$ & $400-2400$ & Sec.-hrs & 6.75 & $30-80$ & $3500 @ 100$ & $10-20$ & 70 & $0.2-0.3$ & -40 to 50 \\
\hline Li-ion & $900-1300$ & Sec.-hrs & $0.001-50$ & $100-200$ & $\begin{array}{c}1500-3500 @ 0 \\
80\end{array}$ & $14-16$ & 75-95 & 1-5 & -30 to 60 \\
\hline VRB & 600 & Sec. $-10 \mathrm{hrs}$ & $2-120$ & $30-50$ & $\begin{array}{c}100-13000 @ \\
75\end{array}$ & $10-20$ & $65-85$ & Very low & 0 to 40 \\
\hline ZBB & 500 & Sec. $-10 \mathrm{hrs}$ & $0.1-4$ & $60-85$ & $2000-2500$ & $8-10$ & $65-85$ & No & 0 to 40 \\
\hline PSB & $300-1000$ & Sec. $-10 \mathrm{hrs}$ & $0.005-120$ & $>400$ & $\begin{array}{c}100-13000 \\
\text { @ } 75\end{array}$ & 15 & $60-75$ & No & 0 to 40 \\
\hline
\end{tabular}

TABLE 3: Battery energy storage system ratings (per module).

\begin{tabular}{|c|c|c|c|c|c|c|c|c|c|c|}
\hline $\begin{array}{l}\text { S. } \\
\text { number }\end{array}$ & Type & $\begin{array}{l}\text { Commercial } \\
\text { product }\end{array}$ & Rating & Voltage & $\begin{array}{c}\text { Life time in } \\
\text { yrs }\end{array}$ & $\begin{array}{c}\text { Charging } \\
\text { efficiency in } \\
\%\end{array}$ & $\begin{array}{c}\text { Discharging } \\
\text { efficiency in } \\
\%\end{array}$ & $\begin{array}{c}\text { Depth of } \\
\text { discharge } \%\end{array}$ & Cost & $\begin{array}{l}\text { Energy } \\
\text { cost } \\
\text { coeff. in } \\
\text { Rs/kWh }\end{array}$ \\
\hline 1 & $\begin{array}{l}\text { Lead- } \\
\text { acid }\end{array}$ & $\begin{array}{c}\text { Trojan } \\
\text { T105-RE }\end{array}$ & $225 \mathrm{Ah}$ & 6 & 10 & 95 & 80 & 70 & $160 \$ /$ module & 6,222 \\
\hline 2 & PSB & & $50 \mathrm{~kW}$ & 48 & 15 & 90 & 75 & 75 & $500 \$ / \mathrm{kWh}$ & 36,000 \\
\hline 3 & VRB & & $50 \mathrm{~kW}$ & 48 & 18 & 98 & 85 & 75 & $600 \$ / \mathrm{kWh}$ & 36,000 \\
\hline 4 & $\mathrm{NaS}$ & & $50 \mathrm{~kW}$ & 48 & 20 & 99 & 88 & 100 & $400 \$ / \mathrm{kWh}$ & 9,000 \\
\hline 5 & $\mathrm{LiPeO}_{4}$ & $\begin{array}{l}\text { Smart battery } \\
\text { SB300 }\end{array}$ & $300 \mathrm{Ah}$ & 12 & 14 & 99 & 95 & 80 & $3500 \$ /$ module & 30,000 \\
\hline
\end{tabular}

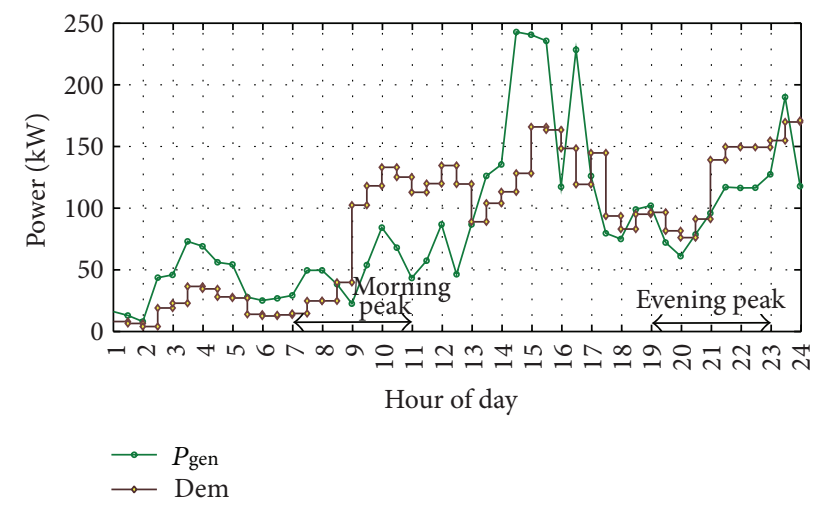

FIGURE 5: Dispatch curve.

respectively. Each cell is composed of an electrolyte with positive and negative electrodes. Electrochemical reactions occur at the electrodes to generate free electrons, which move around generating electrical energy. The amount of energy that can be stored depends upon the mass/volume of electrodes while the power capacity is determined by the contact area of electrodes with the electrolyte. Many battery types are available for integrating renewable systems and their characteristics are tabulated after extensive study in
Table 2. A deeper knowledge on the types of BESS and their characteristics could be gained from [8]. Nickel-cadmium batteries suffer from "memory effect" [26] and are very costly and cause health risks. They are also banned in some countries and are now replaced with other batteries [27]. This study compares five types of batteries which include the conventional (lead acid), Lithium-ion, and fast developing battery systems like sodium and flow batteries. Rechargeable lead-acid batteries have been in the market for more than a decade now. Low self-discharge, easy availability, and low cost make them highly suitable for renewable integration applications. Flow batteries find improved applications in renewable systems for long term storage of energy. This is due to improved scalability, reliability, and recycling capability [28]. Sodium sulphide $(\mathrm{NaS})$ batteries have high energy density and excellent energy efficiency. Lithium-ion batteries have the highest energy density and their portable features and light weight enhance their flexibility and modularity. Of the five batteries, only lead-acid and lithium-ion batteries are available commercially. The characteristics of these are obtained from their data sheets [29] and [30], respectively. The flow batteries and the NaS batteries are assumed to be implemented in $50 \mathrm{~kW}$ modules [31]. The data in Table 3 have been obtained using the data sheets of commercial batteries and other assumptions are taken according to data from Table 2. 
3.2. Sizing of BESS. Let $E_{\text {batt }}$ be the average energy requirement for the battery per day in kWh per day. It is evaluated from the maximum power surplus/deficit $\left(P_{\text {diff }}(t)\right)$ calculated as below where $P_{\text {dem }}(t)$ is the power that is to be dispatched over a time period $\Delta t$. Let $N$ depict the number of days in the simulation period. Consider

$$
\begin{gathered}
P_{\text {diff }}(t)=P_{\text {gen }}(t)-P_{\text {dem }}(t) \\
E_{\text {batt }}(\mathrm{kWh})=\max \left\{\sum_{i=1}^{N} P_{\text {diff }} \times \Delta t\right\} .
\end{gathered}
$$

A simple model of battery is implemented to evaluate the nominal size of the battery system [32]. The model needs to take into account the depth of discharge (DoD\%), days of autonomy $(D)$, and battery aging. DoD is optimally selected for each battery to ensure its longevity and efficiency. It can be seen from Table 3 that NaS batteries have 100\% DoD as they can be completely drained to $0 \%$ SOC, but lead-acid batteries show degraded performance with such a high DoD. "Days of autonomy" indicate the duration for which the battery is capable of meeting the dispatch as a back-up without charging that is assumed to be 2 days in this study. The operating temperatures and aging also affect the operation of the BESS. Hence, from [33] the temperature correction factor for an average operating temperature of $28^{\circ} \mathrm{C}$ (from Figure 7) is found to be 0.964 . The aging characteristics of the battery are considered by assuming an aging factor of $15 \%$. A common correction factor is evaluated in (5) and included in (6) for battery sizing as follows:

Correction factor for effect of temperature \& aging

$$
=(0.964 * 1.15)=1.108 \approx 110 \%
$$

Required Battery capacity in kWh: $E_{\text {batt(max) }}(\mathrm{kWh})$

$$
=\frac{110 E_{\text {batt }}(\mathrm{kWh} / \text { day }) D}{\operatorname{DoD} \%}
$$

Required Battery capacity in Ah: $E_{\text {cap }}$ (Ah)

$$
=\frac{E_{\mathrm{batt}(\max )}(\mathrm{kWh})}{V \times 1000} \text {. }
$$

$E_{\text {cap }}$ is the required capacity of battery in Ah. The ratio of $E_{\text {cap }}$ to the Ah rating of the individual battery module/cell yields the number of batteries to be connected in parallel $\left(N_{p}\right)$. The ratio of system voltage to the voltage rating of the individual battery module/cell gives the number of batteries to be connected in series $\left(N_{s}\right)$, to form the battery bank. Battery size obtained is minimized further by implementing an optimization algorithm by considering $E_{\text {cap }}$ as a maximum boundary limit for the population selection.

3.3. Bat Optimization Algorithm. The underlying idea in most of the optimization algorithms is to emulate a natural process to evaluate the optimum result. Some of the examples of these are genetic algorithm, particle swarm, and simulated annealing algorithms. Bat algorithm is new metaheuristic optimization technique formulated by Yang in 2010 [34] and its literature review and applications are listed in [35]. It is inspired from the prey locating technique called echolocation in flying bats used extensively by microbats. They emit sound pulses and listen for their reflected echo, to infer their surroundings and prey. In bat algorithm, a population of bats is initiated with a fixed pulse emitting frequency, rate, and loudness. Velocities and position of the bats are updated similar to particle swarm optimization. Loudness and rate of pulse emission are updated based on distance from the prey. The pseudocode of the algorithm is shown in Pseudocode 1:

Minimize Annualized Cost $=$ Battery Cost + Losses

$$
\text { Battery Cost }=\left(E_{\text {bess }} \times \chi\right) \times(1+\gamma) \times \mathrm{CRF}
$$

(see [36]), where Capital Recovery Factor is

$$
\begin{aligned}
\mathrm{CRF} & =\frac{\mathrm{idr}(1+\mathrm{idr})^{n}}{(1+\mathrm{idr})^{n}-1} . \\
\mathrm{idr} & =\frac{1+\mathrm{ir}}{1+\mathrm{ifr}}-1 .
\end{aligned}
$$

Here ir denotes interest rate, if $r$ is the inflation rate, idr is the discount rate, and $n$ denotes the lifetime of battery. The objective function is to minimize investment costs and losses and is formulated as summation of two terms. First is battery cost which is a function of battery size $E_{\text {bess }}$ in $\mathrm{kWh}$, which is the optimization variable in the equation. Second term "Losses" include losses incurred due to wind power spilling and load shedding caused by inadequate storage. As the losses have an inversely proportionate relationship with the battery size (a larger battery ensures greater reliability and lesser losses and vice versa), they are included in the cost minimization function. The constraints bounding the optimization problem are as follows:

(1) Power balance constraints is $P_{\text {gen }}(t)=P_{\text {dem }}(t)+P_{b}(t)$.

(2) Battery power limit constraints is $P_{b, \min } \leq P_{b}(t) \leq$ $P_{b, \max }$.

(3) Battery SOC constraints is $\mathrm{SOC}_{\min } \leq \mathrm{SOC}(t) \leq$ $\mathrm{SOC}_{\max }$, where $\operatorname{SOC}(t)=\operatorname{SOC}(t-1)+P_{b}(t) \times$ $\left(\Delta t / E_{\text {bess }}\right)$.

(4) Battery energy limit constraints is $E_{b, \min } \leq E_{b}(t) \leq$ $E_{b, \max }$.

For discharging, $E_{b}(t)=\max \left\{\left(E_{b}(t-1)+(\Delta t \times\right.\right.$ $\left.\left.\left.P_{b}(t)\right) / \eta_{\text {dis }}\right), E_{b, \text { min }}\right\}$.

For charging, $E_{b}(t)=\min \left\{\left(E_{b}(t-1)+\left(\Delta t \times P_{b}(t)\right) \times\right.\right.$ $\left.\left.\eta_{\text {chg }}\right), E_{b, \text { max }}\right\}$.

\section{Performance and Economic/Environmental Analysis of Battery Storage}

The battery operates in charge/discharge mode based on the power surplus/deficit occurring in the HRES. Let $P_{b}(t)$ be the power exchange to and from the battery during charge/discharge, respectively (positive for charging and negative for discharging). The energy management strategy of the HRES system is depicted in the flow chart of Figure 6. 


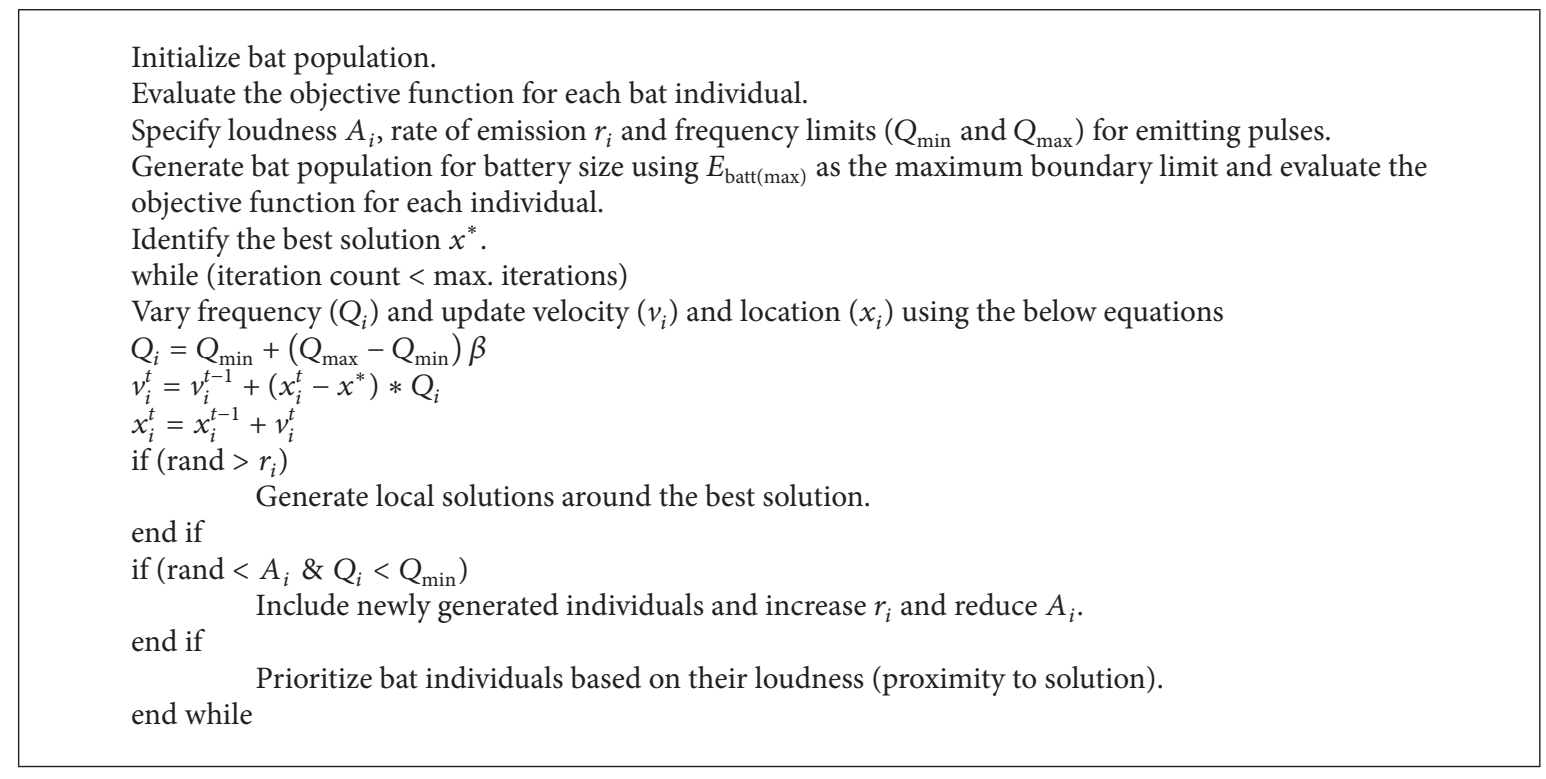

Pseudocode 1

4.1. System Metrics. A feasibility study of the HRES project is determined by evaluating its economic system metrics. The tariff fixed for wind power by the Tamil Nadu Electricity Regulatory Commission [37] is Rs. 2.75 per kWh. Assuming the same to be the price of the HRES power output, the following system metrics are evaluated.

4.1.1. Revenue Losses ( $R L)$. The wind-PV system incurs losses under three conditions.

(i) Wind Power Curtailment. Tamil Nadu faces instances of wind power curtailment due to creaky T\&D infrastructure. This condition occurs when there is sufficient wind, yet the wind turbines are either stalled or generating below rated power due to lack of power evacuation or load-demand mismatch [38]. The actual wind power generated by the wind turbine per day for the month of June 2013 is denoted by $P_{w a v g}$. The curtailed wind power $P_{w c u r t}$ and the resulting revenue loss are evaluated as below where " $i$ " denotes the day of the month:

$$
\begin{aligned}
P_{w \text { curt }}(i) & =P_{w \text { avg }}(i)-P_{w \text { act }}(i) \\
\mathrm{RL}_{w \text { curt }} & =\sum_{i=1}^{30} P_{w \text { curt }} \times P R_{\mathrm{ws}} \times t .
\end{aligned}
$$

(ii) Power Spilled. This condition occurs when $P_{\text {gen }}>P_{\text {dem }}$ and the excess power generated is spilled. Revenue lost due to spilling is calculated for the entire simulation period $T$ as follows:

$$
\begin{aligned}
P_{\text {spil }}(t) & =P_{\text {gen }}(t)-P_{\text {dem }}(t) \\
\mathrm{RL}_{\text {spil }} & =\sum_{t=1}^{T} P_{\text {spil }} \times P R_{\mathrm{ws}} \times t .
\end{aligned}
$$

In this case, the power spilled is assumed as the power which is generated but not dispatched due to lack of demand. It differs from curtailed wind power in the fact that the latter is power in the wind which was not harvested at all as explained above.

(iii) Power Shed. This condition occurs when $P_{\text {gen }}<P_{\text {dem }}$. Without storage, the HRES fails to meet the dispatch curve, hence leading to load shedding. The deficit power is assumed to be met by an alternative energy source like diesel power. A diesel generator meets the excess load at a cost of $P R_{d}$ assumed to be Rs. 22 per kWh. Then the revenue loss to be calculated is

$$
\begin{aligned}
P_{\text {shed }}(t) & =P_{\text {dem }}(t)-P_{\text {gen }}(t) \\
\mathrm{RL}_{\text {shed }} & =\sum_{t=1}^{T} P_{\text {shed }} \times P R_{d} \times t .
\end{aligned}
$$

Thus, the total revenue loss is obtained by summing up individual losses:

$$
\mathrm{RL}=\mathrm{RL}_{w \text { curt }}+\mathrm{RL}_{\text {spil }}+\mathrm{RL}_{\text {shed }}
$$

4.1.2. Payback Period. From the revenue earnings and losses evaluated, the profit gained by adding the battery storage can be calculated. Benefits gained here are limited to increase in earnings and reduction in losses due to inclusion of battery. Consider

$$
\mathrm{BGA}=\left[\left(\mathrm{RE}_{w b}-\mathrm{RE}_{w o b}\right)+\left(\mathrm{RL}_{w o b}-\mathrm{RL}_{w b}\right)\right]
$$

Simple Payback Period (SPBP) is the ratio of investment of battery cost (Inv) to the annual benefits gained from its usage. As this does not include any interest rates, a discounted payback period is also evaluated as in (15). It considers rate of 


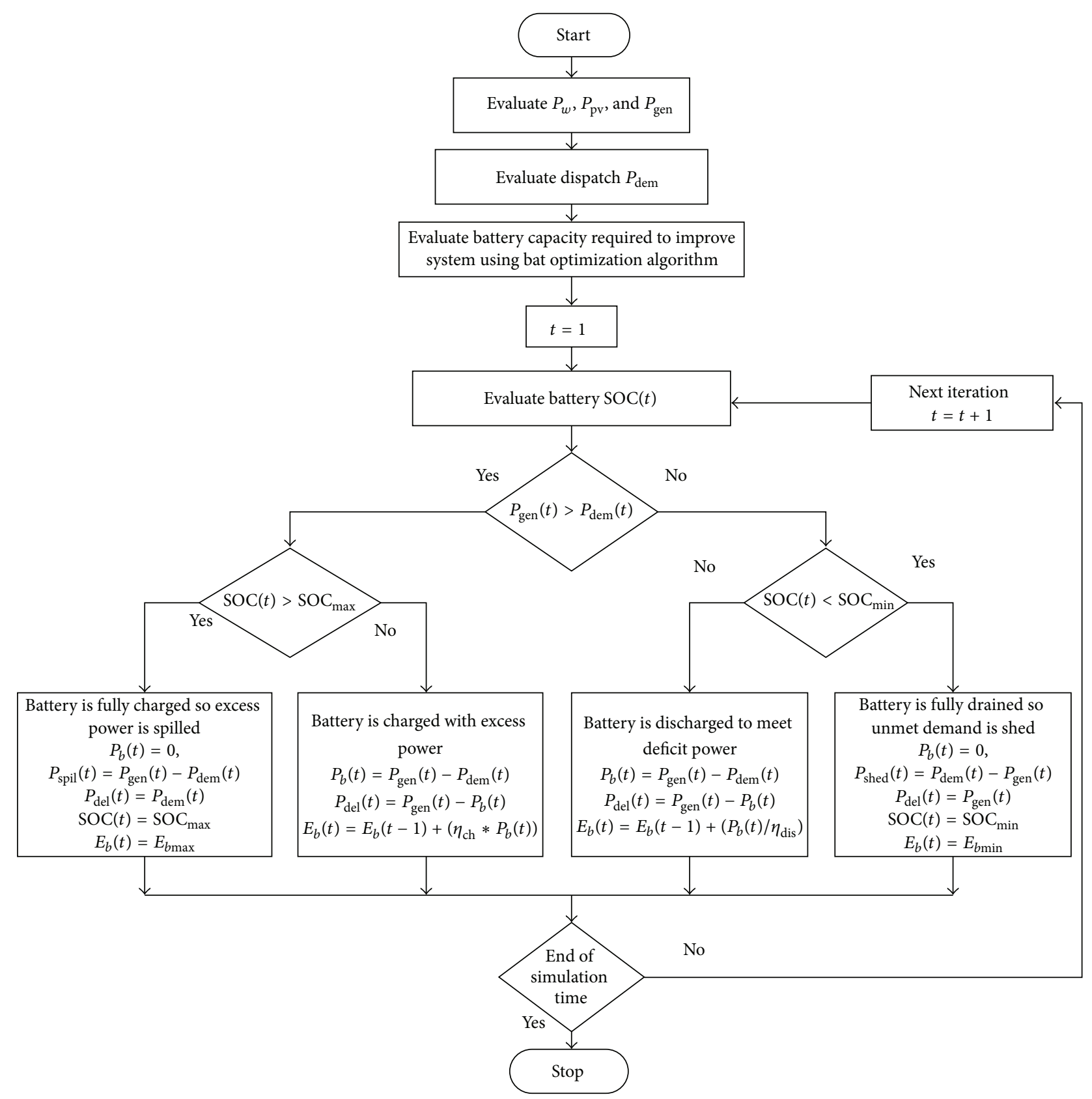

FIGURE 6: Energy management flowchart.

interest, rate of inflation [39], and maintenance and operation charges for the battery as shown in Table 4 . One has

$$
n=-\frac{\ln (1-(\mathrm{idr} \times \operatorname{Inv}) /(\mathrm{BGA}-(\gamma \times \operatorname{Inv})))}{\ln (1+\mathrm{idr})} .
$$

4.1.3. Net Present Value (NPV). The difference between present value of the benefits gained and costs incurred in an investment is termed as the net present value of the system. This is an important economic measure as it includes the time factor with the interest rate. It is always unique irrespective of the cash flow patterns. The formula to calculate NPV is as below. The investment is deemed to be profitable for a positive
NPV and conversion; a negative NPV indicates a financial loss [40]. Consider

$$
\mathrm{NPV}=(\mathrm{BGA})\left[\frac{(1+i)^{n}-1}{i(1+i)^{n}}\right]-\text { Inv. }
$$

4.1.4. Loss of Power Supply Probability (LPSP). It is a reliability index which indicates the measure of energy deficit (DE) in a power system. It is a ratio of the energy deficit in the system to the total energy delivered:

$$
\operatorname{LPSP}=\frac{\sum_{t=1}^{T} \mathrm{DE}(t)}{\sum_{t=1}^{T} P_{\mathrm{del}}(t) \cdot \Delta t} .
$$


TABLE 4: Economic analysis parameters.

\begin{tabular}{lcc}
\hline Symbol & Parameter & Value \\
\hline$P R_{\text {ws }}$ & Wind energy selling price & Rs. 2.75 per kWh \\
$P R_{d}$ & Diesel energy generation & Rs. 22 per kWh \\
ir & Rate of interest & $12 \%$ \\
ifr & Inflation rate & $7 \%$ \\
idr & Discounted rate of interest & $\left(\frac{1+\mathrm{ir}}{1+\mathrm{ifr}}\right)-1$ \\
omr & $\begin{array}{c}\text { O\&M charges of battery as } \\
\% \text { of investment cost }\end{array}$ & $3 \%$ \\
\hline
\end{tabular}

4.1.5. Benefit-Cost Ratio (BCR). The ratio of the benefits to the costs associated with a project investment is its BCR. For a project to be viable, it must yield a BCR ratio greater than unity. It is a profitability index which is most easily interpreted by investors:

$$
\mathrm{BCR}=\left(\frac{\mathrm{BGA} \times \mathrm{CRF}}{\operatorname{Inv} \times(1+\gamma \times \mathrm{CRF})}\right) .
$$

4.1.6. Avoided Cost of Emission (ACE). An analysis on the cost of emission of carbon dioxide is included here. The cost of capture is defined as the incremental levelized capture costs in a given year divided by the volume of $\mathrm{CO}_{2}$ captured for a given year. It is generally expressed as the change in levelized cost of power for a year, between the capture case and the reference case, divided by the volume of $\mathrm{CO}_{2}$ captured in a year. The standard formula is

$$
\mathrm{ACE}_{\mathrm{CO}_{2}}=\frac{\mathrm{COE}_{\text {high }}-\mathrm{COE}_{\text {low }}}{\mathrm{CO}_{2 \text { cap }}},
$$

where COE is the Levelized Cost of Energy from the generation plant. Consider the wind-PV system to be the reference high emission system and the wind-PV-battery system as the low emission system [41]. COE gives the price per unit of energy and is calculated as the sum of the total investment cost of the system and the annual fuel cost of the system [42]. When the load is high the excess load is to be met with a diesel generator, whose rating matches the maximum deficit power. From $P_{\text {diff }}$ evaluated, the maximum power shed can be calculated, that is, for cases $P_{\text {diff }}<0$. This will give the required rating for the diesel generator. In this case, it is $121 \mathrm{~kW}$. The investment cost $\left(\mathrm{DG}_{\mathrm{inv}}\right)$ for a $100 \mathrm{~kW}$ diesel generator is taken to be $6000 \$$ [43] with an average life of 5 years and interest rate of $10 \%$ [41]. Consider

$$
\mathrm{COE}_{\text {high }}=\left(\mathrm{CRF}_{\text {high }} \times \mathrm{DG}_{\text {inv }}\right)+\mathrm{FC}_{\text {ann }},
$$

where $\mathrm{FC}_{\mathrm{ann}}$ is the annual fuel cost for meeting the load and $E_{\text {del }}$ is the energy delivered by the diesel generator at a cost of $P R_{d}$ Rs/kWh. Similarly, $\mathrm{CRF}_{\text {low }}$ and $\mathrm{COE}_{\text {low }}$ are also evaluated.

$\mathrm{CO}_{2 \text { cap }}$ is evaluated as the difference between the amounts of $\mathrm{CO}_{2}$ emitted by the reference high emission system and the low emission battery system. Fuel consumption is assumed
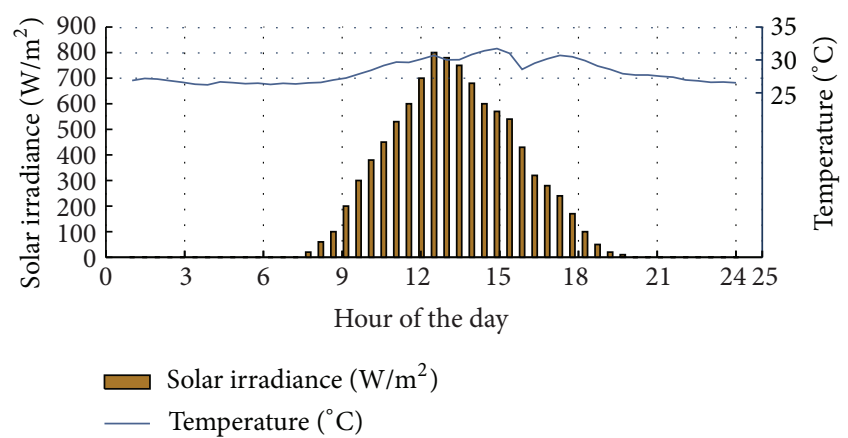

FIGURE 7: Solar irradiance and temperature in $24 \mathrm{hrs}$.

to be 0.33 litres of fuel per kWh energy delivered [44] and $9.63 e-3$ tons of $\mathrm{CO}_{2}$ emitted per gallon of fuel. Thus $(0.33 \times$ $0.264172 \times 9.63 e-3) 0.8395 e-3$ tons of $\mathrm{CO}_{2}$ is emitted per $\mathrm{kWh}$ energy delivered. Then annual emissions will be

$$
\mathrm{CO}_{2 \text { cap }}=\mathrm{CO}_{2 \text { high }}-\mathrm{CO}_{2 \text { low }} \text {. }
$$

\section{Results and Discussions}

5.1. System Description. The specifications of the MICON 450-200 wind turbine are listed in Table 5 [20]. Solar and wind data are recorded over a period of one year at a wind site in Southern India. The solar irradiation data for $24 \mathrm{hrs}$ is shown in Figure 7. The wind data measured (at $30 \mathrm{~m}$ height) for every $10 \mathrm{~min}$ is shown in Figure 8. In India, wind generation is possible only in the windy seasons, that is, May to September. During other months, the generation is too low for consideration. It was observed from site data that the power generated by the wind-PV HRES in one year (inclusive of wind power for 5 months and PV for 12 months) is approximately equal to 5 times the power generated by the system in June alone. Hence, to reduce computational complexity, June is considered as the model month for running the simulation.

5.2. Simulation Results and Discussion. The wind-PV system generated $145.77 \mathrm{MW}$ power in June 2013; of this $90 \%$ was from the wind turbine. The power graph of the wind-PV system without BESS (Figure 9(a)) shows that the delivered power is unable to meet the scheduled dispatch curve. Revenue losses occurring in the system include losses due to wind power curtailment, load spilling, and shedding. These losses add up to a sum of Rs. 450,531.64 annually with a LPSP ratio of $19.72 \%$.

For selection of battery storage systems, five types of batteries, namely lead-acid, sodium sulphide, vanadium redox, polysulphide bromide, and lithium-ion batteries, are considered. Using (6)-(7), the size and investment costs required for each battery are evaluated and the results are tabulated in Table 6. Results illustrate that NaS batteries required the least capacity as compared to others. VRB batteries are found to be the costliest of all other considered options. The battery size is further optimized using bat optimization algorithm to minimize the investment costs and losses incurred. The 
TABLE 5: Specification of MICON M450-200 wind turbine.

\begin{tabular}{lccccc}
\hline S. number & Specification & Value & S. number & Specification & Value \\
\hline 1 & Rated power & $200 \mathrm{~kW}$ & 8 & Cut-off speed & Voltage \\
2 & Rotor diameter & $24 \mathrm{~m}$ & 9 & Freq. & $400 \mathrm{~V}$ \\
3 & Swept area & $452 \mathrm{~m}^{2}$ & 10 & Air density & $1.2258 \mathrm{~kg} / \mathrm{m}^{3}$ \\
4 & Blade length & $12 \mathrm{~m}$ & 11 & Pitch angle & 10 deg. \\
5 & Tip-speed ratio & $52.2 \mathrm{~m} / \mathrm{s}$ & 12 & Efficiency & $95 \%$ \\
6 & Cut-in speed & $5 \mathrm{~m} / \mathrm{s}$ & 13 & & \\
7 & Rated speed & $13 \mathrm{~m} / \mathrm{s}$ & & \\
\hline
\end{tabular}

TABLE 6: Sizing of batteries without optimization.

\begin{tabular}{lccccc}
\hline Type & $\begin{array}{c}\text { Rating in } \\
\text { Ah/module }\end{array}$ & Capacity in Ah & $\begin{array}{c}\text { Number of } \\
\text { modules }\end{array}$ & Inv. in \$ \\
\hline Pb-acid & 225 & 2700 & 240 & $\$ 35,520$ & $2,131,200$ \\
PSB & 1042 & 3126 & 9 & $\$ 225,000$ & $13,500,000$ \\
VRB & 1042 & 3126 & 9 & $\$ 270,000$ & $16,200,000$ \\
NaS & 1042 & 2084 & 6 & $\$ 120,000$ & $7,200,000$ \\
Li-ion & 300 & 2400 & 80 & $\$ 280,000$ & $16,800,000$ \\
\hline
\end{tabular}

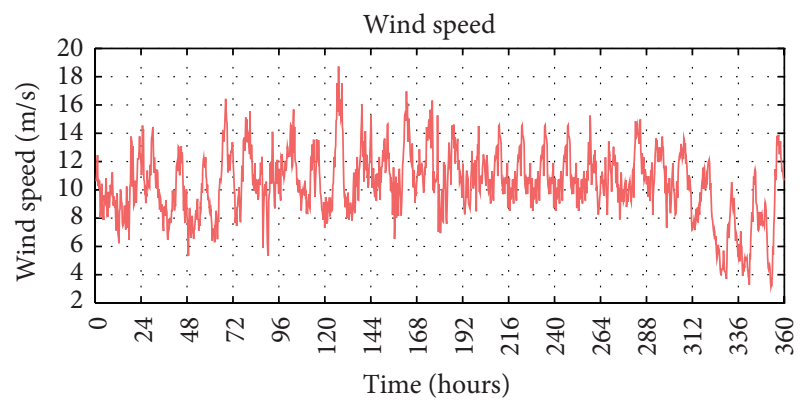

FIGURE 8: Wind speed at $30 \mathrm{~m}$ height.

loudness and the pulse rate of the bat algorithm are set as 0.5 . Results obtained after optimizing are as in Table 7. Optimization of battery size resulted in significant changes in investment costs (Figure 10), payback periods, and BCR values of the system. In case of $\mathrm{NaS}$ batteries, the size is reduced to $50 \%$ as opposed to the battery size evaluated using (7). In other batteries the size is reduced to $30-40 \%$. The battery sizes thus evaluated are about $4-7.5 \%$ ( $4 \%$ for $\mathrm{NaS}$ being the smallest and $7.5 \%$ for flow batteries being the largest) of the rating of the wind-PV HRES. These results are consistent and, in some cases, better than the results obtained in previous literatures. In [45], the battery size evaluated using optimization was $6-10 \%$ and in [14], fuzzy and neural controllers were used to size the energy storage to be $30-$ $34 \%$. A feasibility study by $\mathrm{Ma}$ et al. in [15] proposed a battery size about $24 \%$ of size of the wind-PV isolated system. Another study by Teleke et al. [46] suggests that a battery of size $15-25 \%$ of HRES capacity would be sufficient for effective power dispatch. Thus in the current study, a battery of much smaller size about $4-7.5 \%$ is proved to be sufficient.

Energy delivered and profits gained before and after integration of BESS with the HRES are compared. Energy storage helped to increase the power delivered by $24.56 \%$ and enabled the HRES to meet the scheduled dispatch curve at all times thus reducing the LPSP to zero as illustrated in Figure 9(b). It can be seen that after inclusion of battery storage the power delivered curve follows the dispatch curve scheduled earlier. Losses due to spilling and wind curtailment are reduced to zero and the energy thus saved is utilized to meet peak demand. Tamil Nadu has a fixed wind power tariff rate [37]; hence the profits earned are based on reduction of power losses alone and no additional incentives for time shifting have been considered. Thus, a future introduction of TOU tariffs or incentives may increase the profitability of storages implementing peak shaving.

The total power discharged from the battery to the grid for the duration of the simulation is $28 \mathrm{MW}$ that contributed to $19.72 \%$ of the total power delivered by the wind-PVbattery HRES. Graphs plotted in Figures 11(a) and 11(b) show the power charged and discharged from the battery. The SOCs of the batteries, plotted in Figure 12(a), give an indication on the performance of the battery storages. The SOC values vary within $90-30 \%$ depending on the DoD of each battery indicating effective utilization of the battery size over the period of simulation. Observing the change in SOC for over $48 \mathrm{hrs}$ as shown in Figure 12(b) shows the deeper charges/discharges occurring in a NaS battery due to its maximum DoD. Flow batteries show identical performance but lag behind other batteries due to lower DoD and efficiencies. The life of battery storage systems depends greatly on the cycles of operation preformed. From Figure 12(a), the number of charge/discharge cycles per year in the current study can be evaluated to be about 300-350. Assuming the lifecycle limits of batteries to be 10,000 cycles for flow batteries and 2,000-3,000 cycles for other batteries (as all batteries considered are deep-cycle batteries), lifetime of batteries in years is evaluated to be 6 for $\mathrm{Pb}$-acid, 8.33 for $\mathrm{NaS}, 10$ for Li-ion, and $>20$ for flow batteries. Li et al. [11] 
TABLE 7: Sizing of batteries with optimization.

\begin{tabular}{|c|c|c|c|c|c|}
\hline Type & Rating in $\mathrm{Ah}$ & Capacity in Ah & Number of modules & Inv. in \$ & Inv. in INR \\
\hline $\mathrm{Pb}$-acid & 225 & 1800 & 160 & $\$ 23,680$ & $1,420,800$ \\
\hline PSB & 1042 & 2084 & 6 & $\$ 150,000$ & $9,000,000$ \\
\hline VRB & 1042 & 2084 & 6 & $\$ 180,000$ & $10,800,000$ \\
\hline $\mathrm{NaS}$ & 1042 & 1042 & 3 & $\$ 60,000$ & $3,600,000$ \\
\hline Li-ion & 300 & 1500 & 50 & $\$ 175,000$ & $10,500,000$ \\
\hline
\end{tabular}

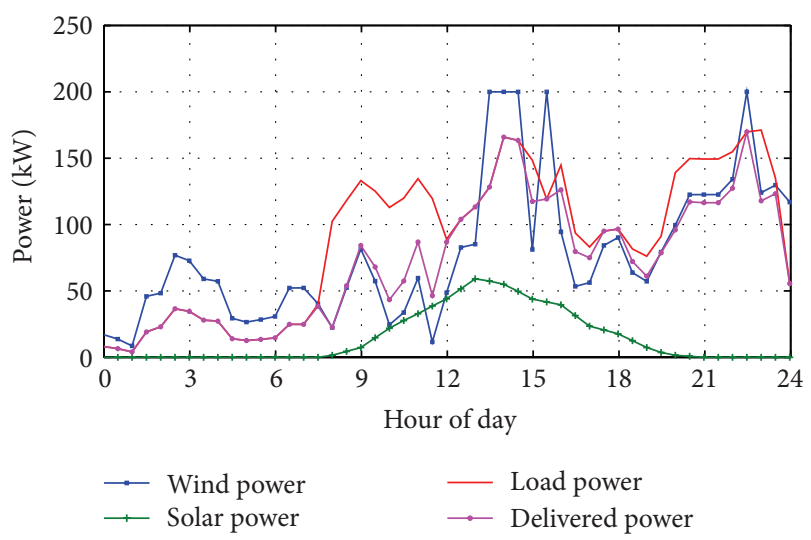

(a)

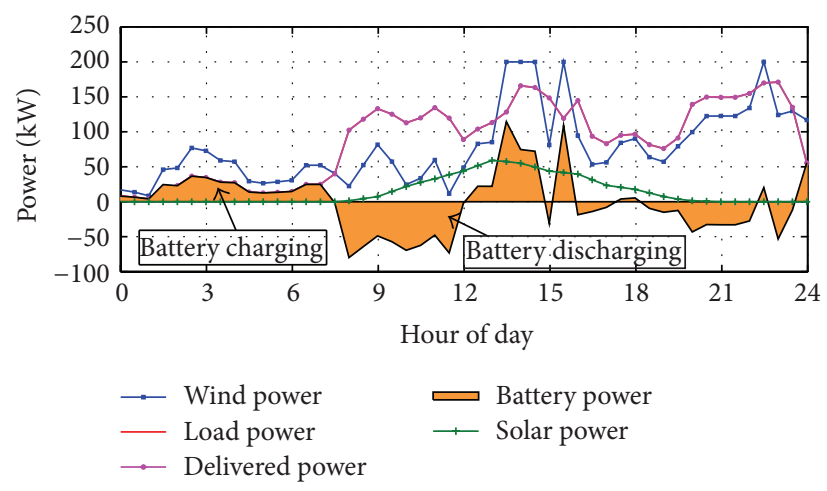

(b)

FIGURE 9: (a) Hybrid system output without battery storage. (b) Hybrid system output with battery storage.

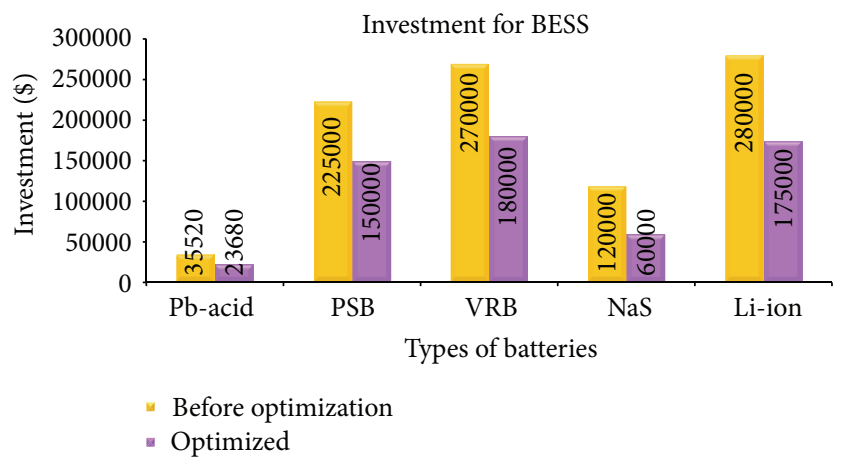

FIGURE 10: Investment for BESS.

developed a dispatch strategy to maximize the lifetime of the battery and simulation results showed an estimated battery life of 2.10 years. Thus, current study results indicate a better lifetime operation of batteries than those shown in earlier literature. It is also to be noted that though the VRB battery was the most expensive it also has highest number of cycles.

The performance of battery system is then evaluated based on operating conditions discussed in [47]. Ah throughput of a battery is the cumulative Ah discharged from battery after normalization with battery capacity. In the current study, the partial cycling index for all the batteries lies in the range of $58-60 \%$ and $\mathrm{Ah}$ throughput index was found to be $67 \%$. "Time at low SOC" value is the percentage operating time for which the battery SOC is below 30\% and is found to be $1.3 \%$. These findings indicate an optimal battery operation (category 5) with low medium risk of aging.
Thus, the sizing strategy with the energy management system results in optimal and intelligent use of battery storage.

System metrics evaluated based on simulation results were tabulated in Tables 8 and 9. Investment costs are shown in rupees with exchange rate assumed to be Rs.60/- per dollar. As the delivered power is the same for all battery cases, the monetary benefits gained remain equal. As BCR ratios for all batteries are positive it can be assured that all battery systems operate profitably. NaS batteries have the lowest capacity requirements with high efficiency. $\mathrm{Pb}$-acid batteries are the cheapest needing investment of only $59 \%$ of the cost of NaS batteries. Hence, they have the lowest payback period (see Figure 13) of less than a year and highest BCR (see Figure 14) of 10.95. However, NaS batteries have maximum NPV (see Figure 15), thus indicating that they can be an economically sound choice with zero maintenance. This is further supported by the fact that NaS battery has nearly twice the lifetime of lead-acid battery. The drawback of the NaS battery is that it can be operated only at high temperatures and require adequate thermal management.

Flow batteries and Li-ion battery have longer payback periods and higher investment costs. This makes them the least favorable compared to lead-acid and $\mathrm{NaS}$ batteries. However, the payback periods are only a quarter of their lifetimes, beyond which all benefits earned will be considered as profits. Any reduction in prices of these batteries in the near future may attract investments. Also, VRB and PSB showed the longest cycle life based on operating cycles. Recently, VRB batteries are being installed commercially and are attracting investors due to the recyclability of electrolyte and low maintenance issues (maintenance required only for 


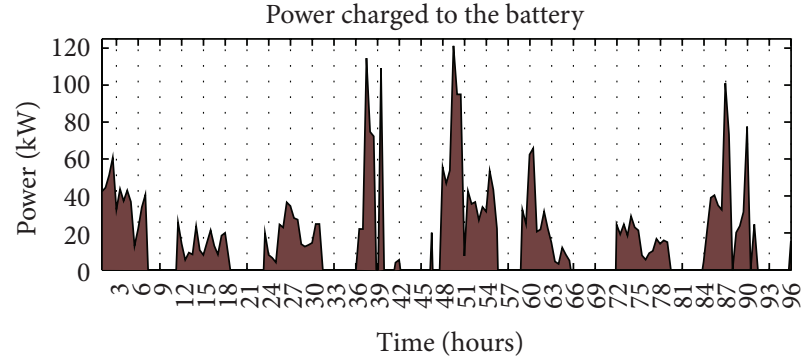

(a)

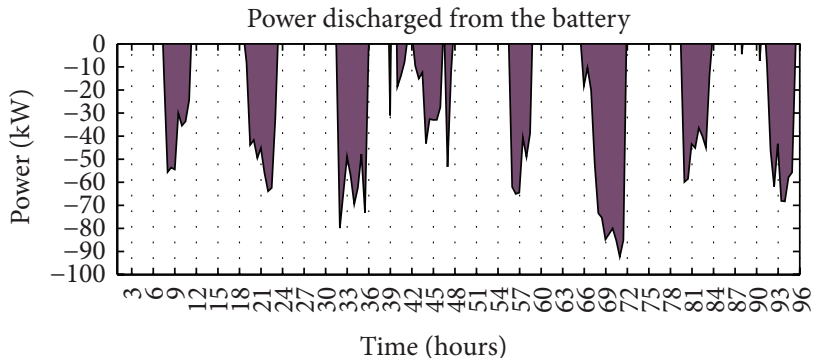

(b)

Figure 11: (a) Power charged to the battery. (b) Power discharged from the battery.

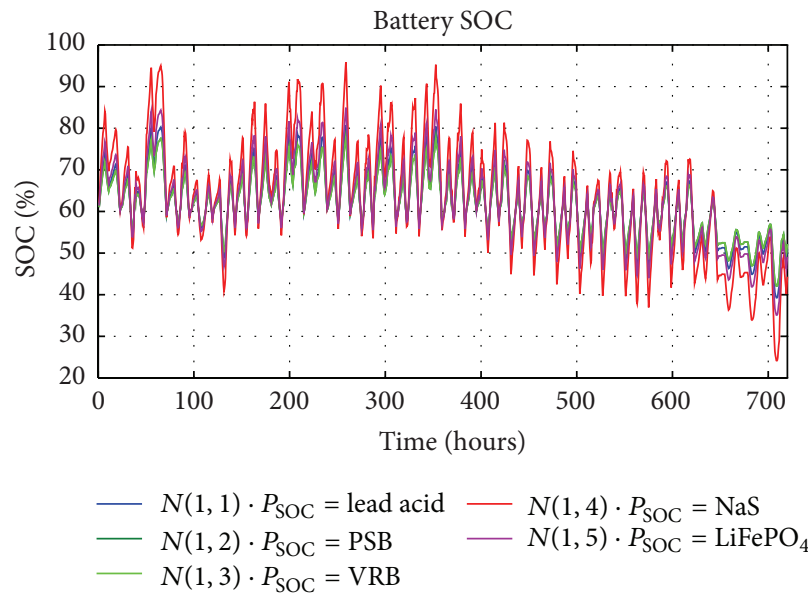

(a)

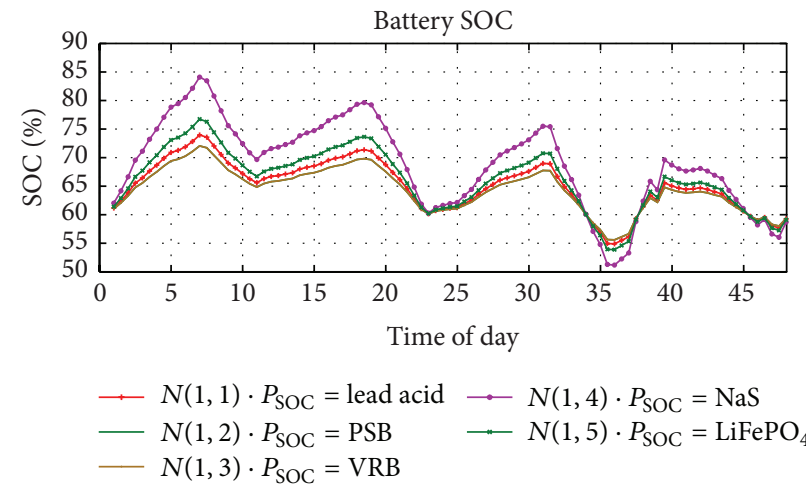

(b)

FIGURE 12: (a) SOC of batteries. (b) SOC of batteries for $48 \mathrm{hrs}$.

TABLE 8: Economic analysis without optimization.

\begin{tabular}{lccccccccc}
\hline Type & $\begin{array}{c}\text { Energy } \\
\text { delivered in } \\
\text { kWh }\end{array}$ & $\begin{array}{c}\text { Revenue } \\
\text { earned (INR) }\end{array}$ & $\begin{array}{c}\text { Benefits in } \\
\text { INR for June }\end{array}$ & $\begin{array}{c}\text { Annual } \\
\text { benefits in } \\
\text { INR }\end{array}$ & NPV & SPBP in yrs & DPBP in yrs & BCR & ACE in INR \\
\hline Pb-acid & 73,049 & 200,884 & 490,146 & $2,450,730$ & $16,595,301$ & 0.87 & 0.93 & 7.30 & $21,539.00$ \\
PSB & 73,049 & 200,884 & 490,146 & $2,450,730$ & $8,211,364$ & 5.51 & 8.07 & 1.46 & $-5,005.00$ \\
VRB & 73,049 & 200,884 & 490,146 & $2,450,730$ & $7,365,298$ & 6.61 & 10.66 & 1.33 & $-9,180.00$ \\
NaS & 73,049 & 200,884 & 490,146 & $2,450,730$ & $21,438,573$ & 2.94 & 3.57 & 3.15 & $11,836.00$ \\
Li-ion & 73,049 & 200,884 & 490,146 & $2,450,730$ & $2,879,398$ & 6.86 & 11.30 & 1.13 & $-14,142.00$ \\
\hline
\end{tabular}

TABLE 9: Economic analysis after optimization.

\begin{tabular}{|c|c|c|c|c|c|c|c|c|c|}
\hline Type & $\begin{array}{c}\text { Energy } \\
\text { delivered } \\
\text { in kWh }\end{array}$ & $\begin{array}{c}\text { Revenue } \\
\text { earned } \\
\text { (INR) }\end{array}$ & $\begin{array}{l}\text { Benefits in } \\
\text { INR for June }\end{array}$ & $\begin{array}{c}\text { Annual } \\
\text { benefits in } \\
\text { INR }\end{array}$ & NPV & SPBP in yrs & DPBP in yrs & BCR & ACE in INR \\
\hline $\mathrm{Pb}$-acid & 73,049 & $200,883.85$ & $490,146.05$ & $2,450,730.23$ & $17,472,912.71$ & 0.58 & 0.61 & 10.95 & $2,3618.00$ \\
\hline PSB & 73,049 & $200,883.85$ & $490,146.05$ & $2,450,730.23$ & $14,144,121.35$ & 3.67 & 4.69 & 2.19 & $5,923.00$ \\
\hline VRB & 73,049 & $200,883.85$ & $490,146.05$ & $2,450,730.23$ & $14,708,352.93$ & 4.41 & 5.93 & 2.00 & $3,140.00$ \\
\hline $\mathrm{NaS}$ & 73,049 & $200,883.85$ & $490,146.05$ & $2,450,730.23$ & $26,422,617.02$ & 1.47 & 1.63 & 6.30 & $19,806.00$ \\
\hline Li-ion & 73,049 & $200,883.85$ & $490,146.05$ & $2,450,730.23$ & $11,089,989.38$ & 4.28 & 5.72 & 1.81 & $15,78.00$ \\
\hline
\end{tabular}




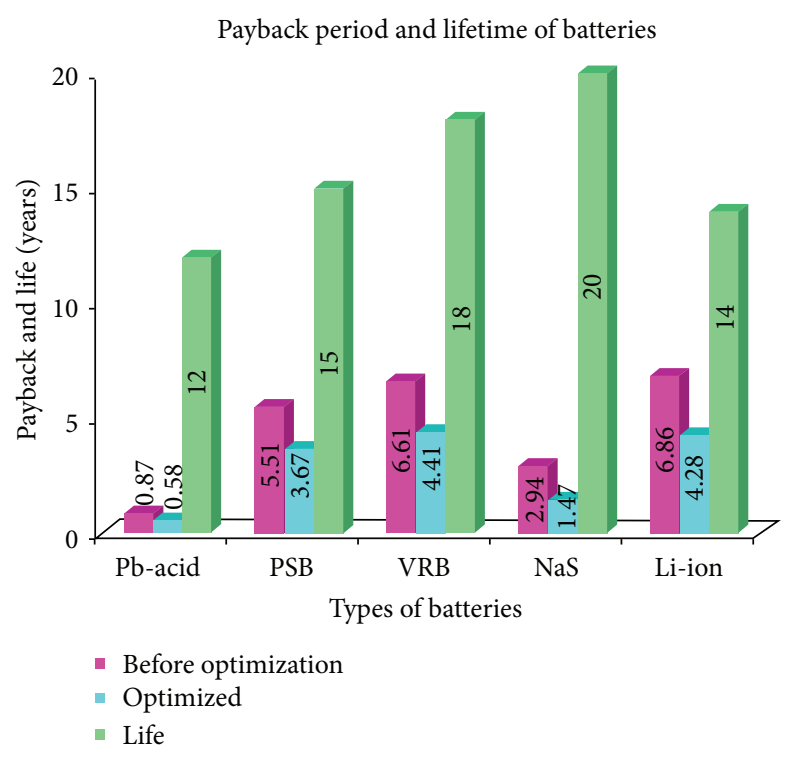

FIgURe 13: Payback period and lifetime of batteries.

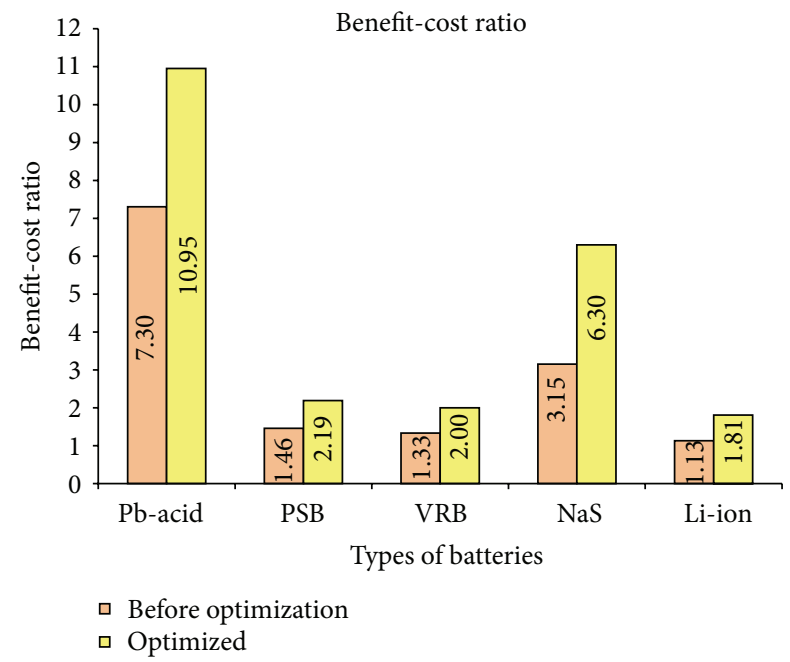

Figure 14: Benefit-cost ratios.

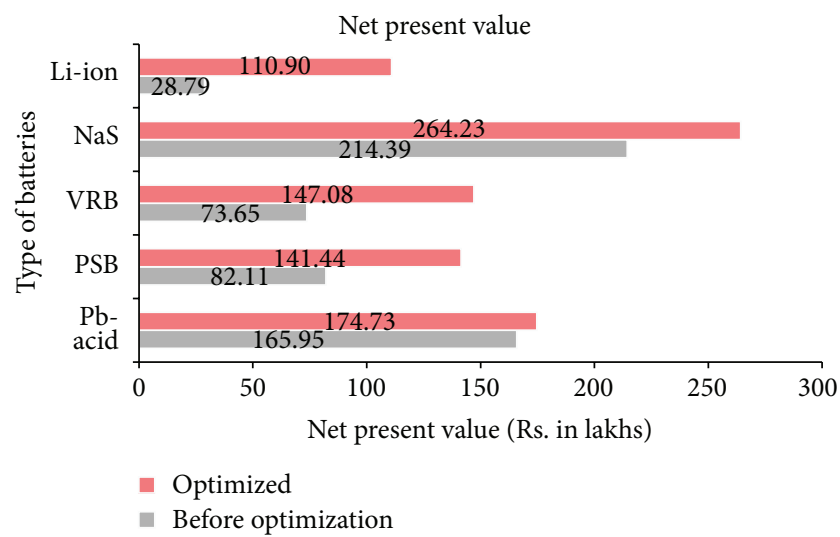

FIGURE 15: Net present value.

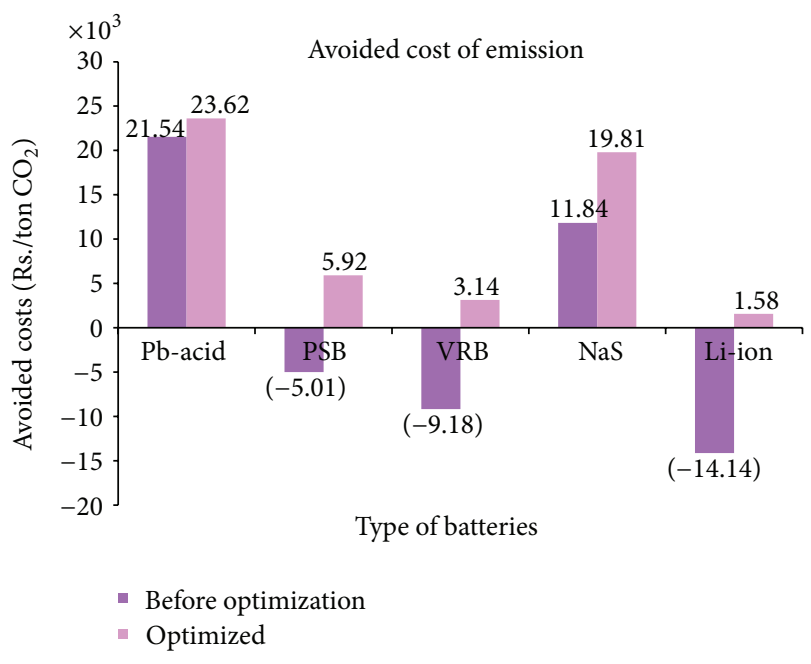

Figure 16: Avoided cost of emission.

the pump systems of the battery). Flow batteries thus are a very promising solution for grid-integrated systems.

It is difficult to justify the investments in green energy or any other sustainable energy which usually requires high investments. It is difficult to set a price for a pollution-free environment. However, introduction of terms like avoided cost of emissions and avoided costs of energy have made it possible to show the profits gained by adopting green power. Hence, to further the idea of integrating energy storages, an environmental analysis is done based on ACE. A diesel generator to meet deficit power in the absence of storage is assumed to be the reference higher emission system. The total annual $\mathrm{CO}_{2}$ emissions from a diesel generator are assumed to be 60.466 tons for calculating the ACE. The chart in Figure 16 shows the avoided cost of emissions obtained by adopting battery systems in the HRES before and after optimization. Prior to optimization, only $\mathrm{Pb}$-Acid and $\mathrm{NaS}$ batteries exhibit savings. However, on optimizing the size of the batteries, the cost of energy for the battery reduces below that of the diesel generator system, thus giving a positive ACE. The avoided costs can also be looked up as savings as they are the difference in cost of energy values of the two systems.

\section{Conclusion}

India is poised for a significant transformation in the renewable power sector. This further emphasizes the necessity of energy storages to make renewable power dispatchable. This study outlines an optimized sizing methodology for battery storage to implement peak shaving and ramp rate limiting features in the power dispatch. The optimization uses bat algorithm to effectively minimize the cost of the battery under fixed tariff. It is then validated in a Wind-PV grid-connected hybrid system to eliminate power curtailment losses and improve power evacuation. The methodology is tested on five types of battery systems from conventional lead-acid and Liion to upcoming flow batteries and $\mathrm{NaS}$ battery. Economic and environmental parameters are evaluated to analyze the 
feasibility of the HRES. The following conclusions could be drawn:

(1) The dispatch strategy and the sizing methodology incorporated peak shaving and ramp rate limiting to effectively optimize the battery size. Consistent and competitive results were obtained, as compared to other referred literature studies.

(2) Though battery storage systems require high initial investments, this study proves that the benefits gained in form of increased reliability and reduced losses justify investments. Profits gained by cutting down on spilling and shedding losses (with 0\% LPSP) were used as payback for recovering the investments.

(3) The lead-acid battery is found to have the least investment costs and shortest payback periods. However, $\mathrm{NaS}$ battery outperformed the lead-acid battery in SOC characteristics with highest NPV. Hence, they provide a better solution with reduced maintenance problems and longer life.

(4) Though Li-ion batteries are highly efficient, the high capital investment costs make them least favorable. Flow batteries proved to be less beneficial with high initial costs but are still an intelligent choice with highest cycle life.

Thus, battery storages are a viable and profitable option for aiding Indian renewable power projects. Future deregulation of power markets and introduction of time based profits will prove beneficiary to systems integrating energy storages. Future work may focus on integration, operation, and control of the battery system with the grid-connected HRES.

\section{Nomenclature}

$\begin{array}{ll}\alpha: & \text { Temperature coefficient of PV panel } \\ \beta: & \text { Pitch angles in degrees } \\ \gamma: & \text { Ratio of maintenance cost to the fixed cost } \\ & \text { of the battery } \\ \omega: & \text { Rotor speed in } \mathrm{rad} / \mathrm{s} \\ \rho: & \text { Air density in } \mathrm{kg} / \mathrm{m}^{3} \\ \lambda: & \text { Tip-speed ratio of the wind turbine } \\ \chi: & \text { Energy cost coefficient of the battery in } \\ \eta_{\mathrm{wt}}: & \text { Rs/kWh } \\ \eta_{\mathrm{pv}}: & \text { Efficiency of the wind turbine } \\ \eta_{\mathrm{ch}} \text { and } \eta_{\mathrm{dis}}: & \text { Charging/discharging efficiency of the } \\ & \text { battery } \\ A: & \text { Swept area in }{ }^{2} \\ C_{p}(\lambda, \beta): & \text { Power coefficient of the wind turbine } \\ E_{b}(t): & \text { Energy stored in the battery at time } t \text { in } \\ E_{\mathrm{bess}}: & \text { kWh } \\ f_{\mathrm{pv}}: & \text { Capacity of battery energy storage system } \\ G_{c}: & \text { in kWh } \\ & \text { Derating factor for solar panel } \\ & \text { Solar irradiance incident on the panel in } \\ & \text { W/m }{ }^{2}\end{array}$

$G_{\text {STC }}$ : Solar irradiance incident on the panel under standard test conditions in $\mathrm{W} / \mathrm{m}^{2}$

$n$ : $\quad$ Discounted payback period in years

$P_{b}(t)$ Power charged/discharged to/from the battery at time $t$

$P_{\text {del }}: \quad$ Power delivered at time $t$

$P_{\text {dem }}$ : Power to be dispatched to the load center in $\mathrm{kW}$

$P_{\text {gen }}: \quad$ Power generated by the wind-PV generation system in $\mathrm{kW}$

$P_{\mathrm{pv}}: \quad$ Power generated by the solar panel in $\mathrm{kW}$

$P_{\text {rated-wt }}:$ Rated power of the wind turbine in $\mathrm{kW}$

$P_{\text {shed }}$ : Load shed due to unavailability of power in $\mathrm{kW}$

$P_{\text {spil }}$ : Wind power lost due to spilling in $\mathrm{kW}$

$P_{w}$ : $\quad$ Power generated by wind turbine in $\mathrm{kW}$

$P_{\text {wact }}: \quad$ Actual wind power extracted from turbine in $\mathrm{kW}$

$P_{\text {wavg }}: \quad$ Average wind power generated as per power curve equation in $\mathrm{kW}$

$P R_{d}: \quad$ Diesel power cost in $\mathrm{Rs} / \mathrm{kWh}$

$P R_{\mathrm{ws}}$ : $\quad$ Selling price of wind power in $\mathrm{Rs} / \mathrm{kWh}$

$R: \quad$ Length of blade in $\mathrm{m}$

SOC $(t)$ : State Of Charge of the battery at time $t$

$T_{c}$ : $\quad$ PV panel temperature in ${ }^{\circ} \mathrm{C}$

$T_{\text {STC }}$ : PV panel temperature under standard test conditions in ${ }^{\circ} \mathrm{C}$

$v$ : $\quad$ Wind speed in $\mathrm{m} / \mathrm{s}$

$v_{\mathrm{ci}}: \quad$ Cut-in speed in $\mathrm{m} / \mathrm{s}$

$v_{\text {co }}: \quad$ Cut-off speed in $\mathrm{m} / \mathrm{s}$

$v_{r}$ : $\quad$ Rated wind speed of turbine in $\mathrm{m} / \mathrm{s}$

$Y_{\mathrm{pv}}$ : Rating of solar panel in $\mathrm{kW}$.

\section{Conflict of Interests}

The authors declare that there is no conflict of interests regarding the publication of this paper.

\section{References}

[1] REN21, Renewables 2015 Global Status Report, REN21 Secretariat, Paris, France, 2015.

[2] http://mnre.gov.in/file-manager/advertisement/EoI-EnergyStorage-Demonstration-Project-for-supporting-RenewableGeneration.pdf.

[3] H. Zhao, Q. Wu, S. Hu, H. Xu, and C. N. Rasmussen, "Review of energy storage system for wind power integration support," Applied Energy, vol. 137, pp. 545-553, 2015.

[4] A. Poullikkas, "A comparative overview of large-scale battery systems for electricity storage," Renewable and Sustainable Energy Reviews, vol. 27, pp. 778-788, 2013.

[5] A. Maleki and A. Askarzadeh, "Optimal sizing of a $\mathrm{PV} /$ wind/diesel system with battery storage for electrification to an off-grid remote region: a case study of Rafsanjan, Iran," Sustainable Energy Technologies and Assessments, vol. 7, pp. 147-153, 2014.

[6] A. Maleki and F. Pourfayaz, "Sizing of stand-alone photovoltaic/wind/diesel system with battery and fuel cell storage 
devices by harmony search algorithm," Journal of Energy Storage, vol. 2, pp. 30-42, 2015.

[7] G. N. Prodromidis and F. A. Coutelieris, "Simulations of economical and technical feasibility of battery and flywheel hybrid energy storage systems in autonomous projects," Renewable Energy, vol. 39, no. 1, pp. 149-153, 2012.

[8] A. H. Fathima and K. Palanisamy, "Battery energy storage applications in wind integrated systems-a review," in Proceedings of the IEEE International Conference on Smart Electric Grid (ISEG '14), pp. 1-8, Guntur, India, September 2014.

[9] M. Gitizadeh and H. Fakharzadegan, "Battery capacity determination with respect to optimized energy dispatch schedule in grid-connected photovoltaic (PV) systems," Energy, vol. 65, pp. 665-674, 2014.

[10] B. Bahmani-Firouzi and R. Azizipanah-Abarghooee, "Optimal sizing of battery energy storage for micro-grid operation management using a new improved bat algorithm," International Journal of Electrical Power and Energy Systems, vol. 56, pp. 4254, 2014.

[11] Q. Li, S. S. Choi, Y. Yuan, and D. L. Yao, "On the determination of battery energy storage capacity and short-term power dispatch of a wind farm," IEEE Transactions on Sustainable Energy, vol. 2, no. 2, pp. 148-158, 2011.

[12] M. P. Johnson, A. Bar-Noy, O. Liu, and Y. Feng, "Energy peak shaving with local storage," Sustainable Computing: Informatics and Systems, vol. 1, no. 3, pp. 177-188, 2011.

[13] M. Dicorato, G. Forte, M. Pisani, and M. Trovato, "Planning and operating combined wind-storage system in electricity market," IEEE Transactions on Sustainable Energy, vol. 3, no. 2, pp. 209217, 2012.

[14] T. K. A. Brekken, A. Yokochi, A. von Jouanne, Z. Z. Yen, H. M. Hapke, and D. A. Halamay, "Optimal energy storage sizing and control for wind power applications," IEEE Transactions on Sustainable Energy, vol. 2, no. 1, pp. 69-77, 2011.

[15] T. Ma, H. Yang, and L. Lu, "A feasibility study of a stand-alone hybrid solar-wind-battery system for a remote island," Applied Energy, vol. 121, pp. 149-158, 2014.

[16] W. Haaf, K. Friedrich, G. Mayr, and J. Schlaich, "Solar chimneys part 1: principle and construction of the pilot plant in manzanares," International Journal of Solar Energy, vol. 2, no. 1, pp. 3-20, 1983.

[17] R. M. Nejad, "A survey on performance of photovoltaic systems in Iran," Iranica Journal of Energy \& Environment, vol. 6, no. 2, pp. 77-85, 2015.

[18] A. Kaabeche and R. Ibtiouen, "Techno-economic optimization of hybrid photovoltaic/wind/diesel/battery generation in a stand-alone power system," Solar Energy, vol. 103, pp. 171-182, 2014.

[19] R. Dufo-López, "Optimisation of size and control of gridconnected storage under real time electricity pricing conditions," Applied Energy, vol. 140, pp. 395-408, 2015.

[20] http://en.wind-turbine-models.com/turbines/256-micon-m450.

[21] A. Junyent-Ferré, O. Gomis-Bellmunt, A. Sumper, M. Sala, and M. Mata, "Modeling and control of the doubly fed induction generator wind turbine," Simulation Modelling Practice and Theory, vol. 18, no. 9, pp. 1365-1381, 2010.

[22] C. Li, X. Ge, Y. Zheng et al., "Techno-economic feasibility study of autonomous hybrid wind/PV/battery power system for a household in Urumqi, China," Energy, vol. 55, pp. 263-272, 2013.

[23] http://www.srldc.org/Role\%20Of\%20SRLDC.aspx.
[24] F. Díaz-González, A. Sumper, O. Gomis-Bellmunt, and R. Villafáfila-Robles, "A review of energy storage technologies for wind power applications," Renewable and Sustainable Energy Reviews, vol. 16, no. 4, pp. 2154-2171, 2012.

[25] H. Chen, T. N. Cong, W. Yang, C. Tan, Y. Li, and Y. Ding, "Progress in electrical energy storage system: a critical review," Progress in Natural Science, vol. 19, no. 3, pp. 291-312, 2009.

[26] http://www.zbattery.com/Battery-Memory-Effect, http://en.wikipedia.org/wiki/Memory_effect.

[27] http://en.wikipedia.org/wiki/Nickel\%E2\%80\%93cadmium_ battery.

[28] http://energystorage.org/energy-storage/technologies/redoxflow-batteries.

[29] http://www.trojanbattery.com/pdf/datasheets/T105RE_TrojanRE_Data_Sheets.pdf.

[30] http://www.lithiumion-batteries.com/products/12v-300ahlithium-ion-battery.

[31] http://www.tepco.co.jp/en/corpinfo/consultant/benefit/1-nas-e .html.

[32] Á. A. Bayod-Rújula, M. E. Haro-Larrodé, and A. MartínezGracia, "Sizing criteria of hybrid photovoltaic-wind systems with battery storage and self-consumption considering interaction with the grid," Solar Energy, vol. 98, pp. 582-591, 2013.

[33] Tri-Service Electrical Working Group (TSEWG), TSEWG TP-4: Stationary Battery and Charger Sizing, 2008, https://www.wbdg .org/ccb/DOD/STC/twewg_tp4.pdf.

[34] X. Yang, "A new metaheuristic bat-inspired algorithm," in Nature Inspired Cooperative Strategies for Optimization (NICSO 2010), vol. 284 of Studies in Computational Intelligence, pp. 6574, Springer, Berlin, Germany, 2010.

[35] X.-S. Yang, "Bat algorithm: literature review and applications," International Journal of Bio-Inspired Computation, vol. 5, no. 3, pp. 141-149, 2013.

[36] Y. Luo, L. Shi, and G. Tu, "Optimal sizing and control strategy of isolated grid with wind power and energy storage system," Energy Conversion and Management, vol. 80, pp. 407-415, 2014.

[37] Tamil Nadu Electricity Regulatory Commission, "Determination of tariff for generation and distribution," T.P. No. 1 of 2013, June 2013.

[38] B. Stoltenberg, K. Clark, and S. K. Negi, "Market-based Indian grid integration study options," in Proceedings of the World Renewable Energy Forum, Denver, Colo, USA, May 2012, http://www.nrel.gov/docs/fyl2osti/54373.pdf.

[39] http://www.inflation.eu/inflation-rates/india/historic-inflation/ cpi-inflation-india-2014.aspx.

[40] T. C. Kandpal and H. P. Garg, Financial Evaluation of Renewable Energy Technologies, Macmillan India, 2003.

[41] R. W. Wies, R. A. Johnson, A. N. Agrawal, and T. J. Chubb, "Economic analysis and environmental impacts of a PV with diesel-battery system for remote villages," in Proceedings of the IEEE Power Engineering Society General Meeting, vol. 2, pp. 1898-1905, Denver, Colo, USA, June 2004.

[42] A. K. Srivastava, A. A. Kumar, and N. N. Schulz, "Impact of distributed generations with energy storage devices on the electric grid," IEEE Systems Journal, vol. 6, no. 1, pp. 110-117, 2012.

[43] http://www.alibaba.com/showroom/100kw-diesel-generatorprice.html.

[44] http://www.netprorenewable.com/techno_eco.html. 
[45] L. Xu, X. Ruan, C. Mao, B. Zhang, and Y. Luo, "An improved optimal sizing method for wind-solar-battery hybrid power system," IEEE Transactions on Sustainable Energy, vol. 4, no. 3, pp. 774-785, 2013.

[46] S. Teleke, M. E. Baran, S. Bhattacharya, and A. Q. Huang, "Rulebased control of battery energy storage for dispatching intermittent renewable sources," IEEE Transactions on Sustainable Energy, vol. 1, no. 3, pp. 117-124, 2010.

[47] V. Svoboda, H. Wenzl, R. Kaiser et al., "Operating conditions of batteries in off-grid renewable energy systems," Solar Energy, vol. 81, no. 11, pp. 1409-1425, 2007. 

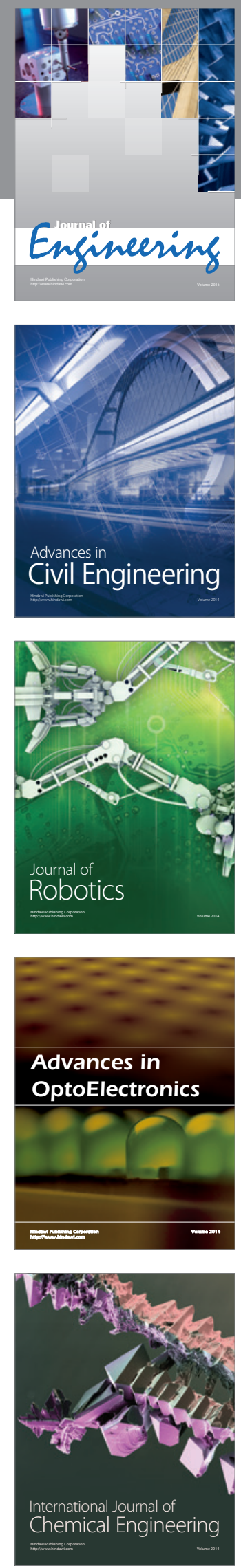

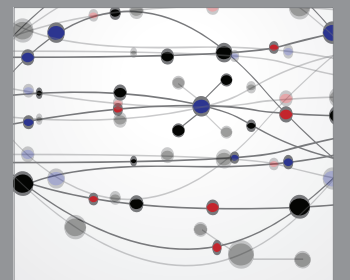

The Scientific World Journal
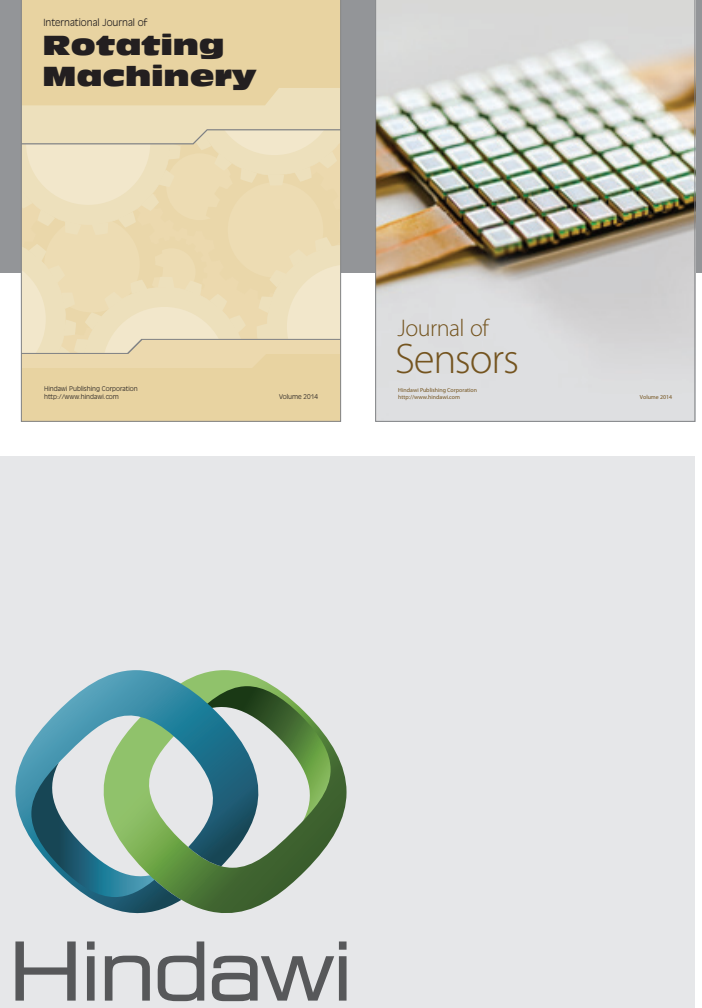

Submit your manuscripts at http://www.hindawi.com
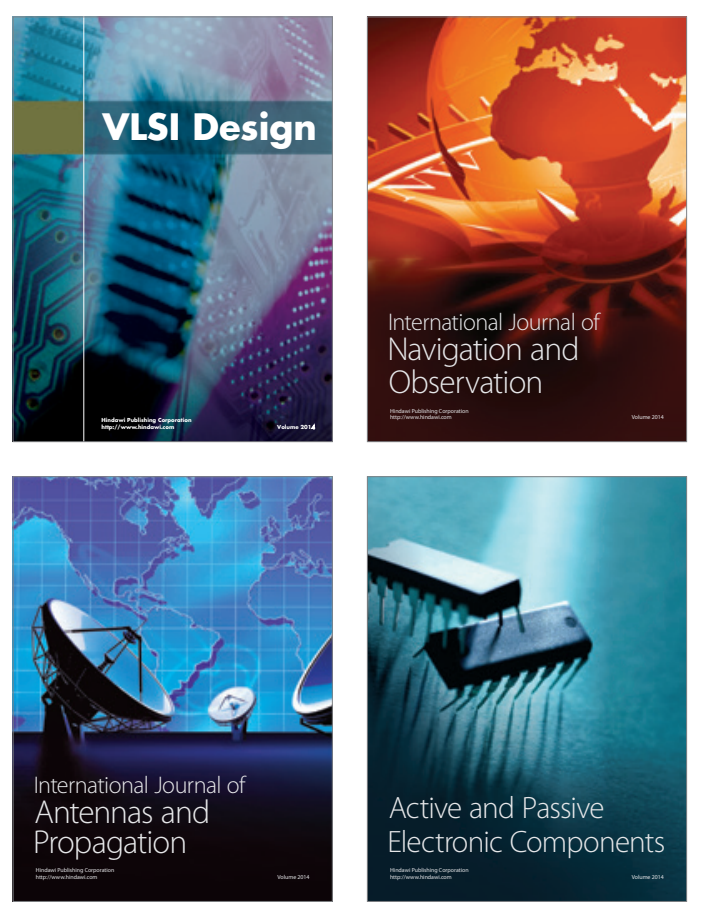
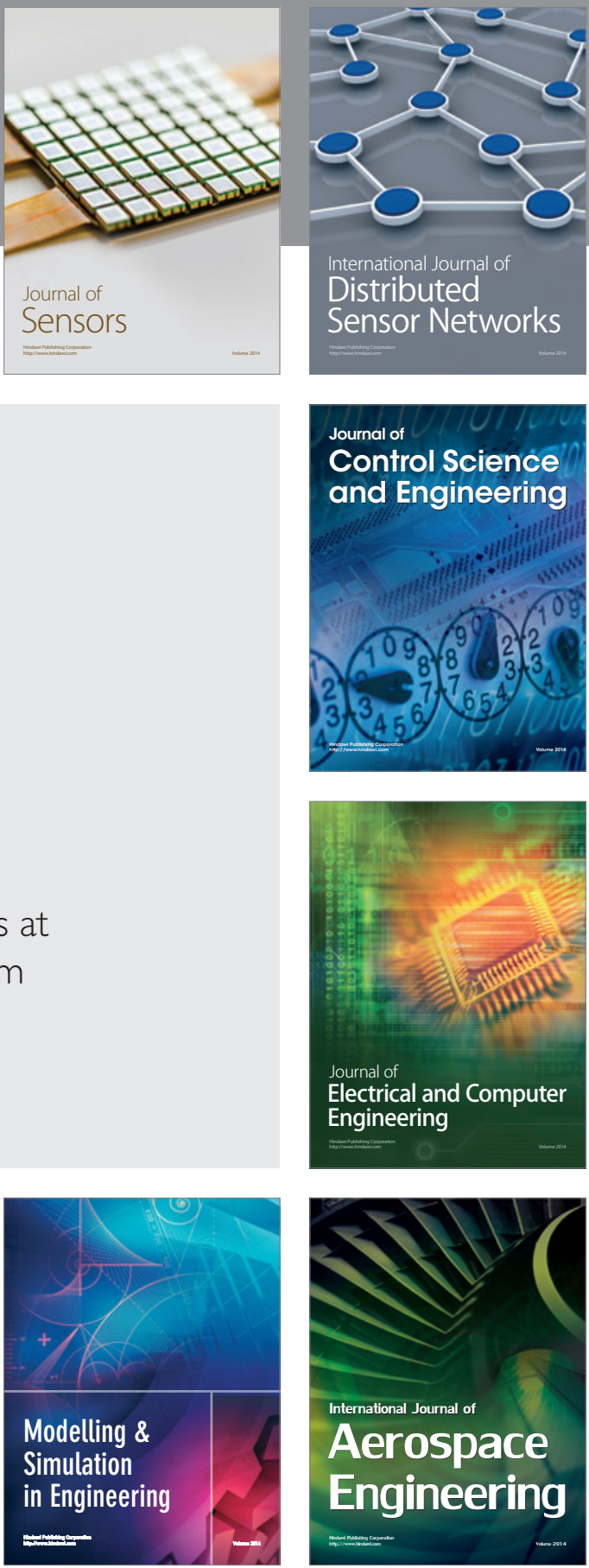

Journal of

Control Science

and Engineering
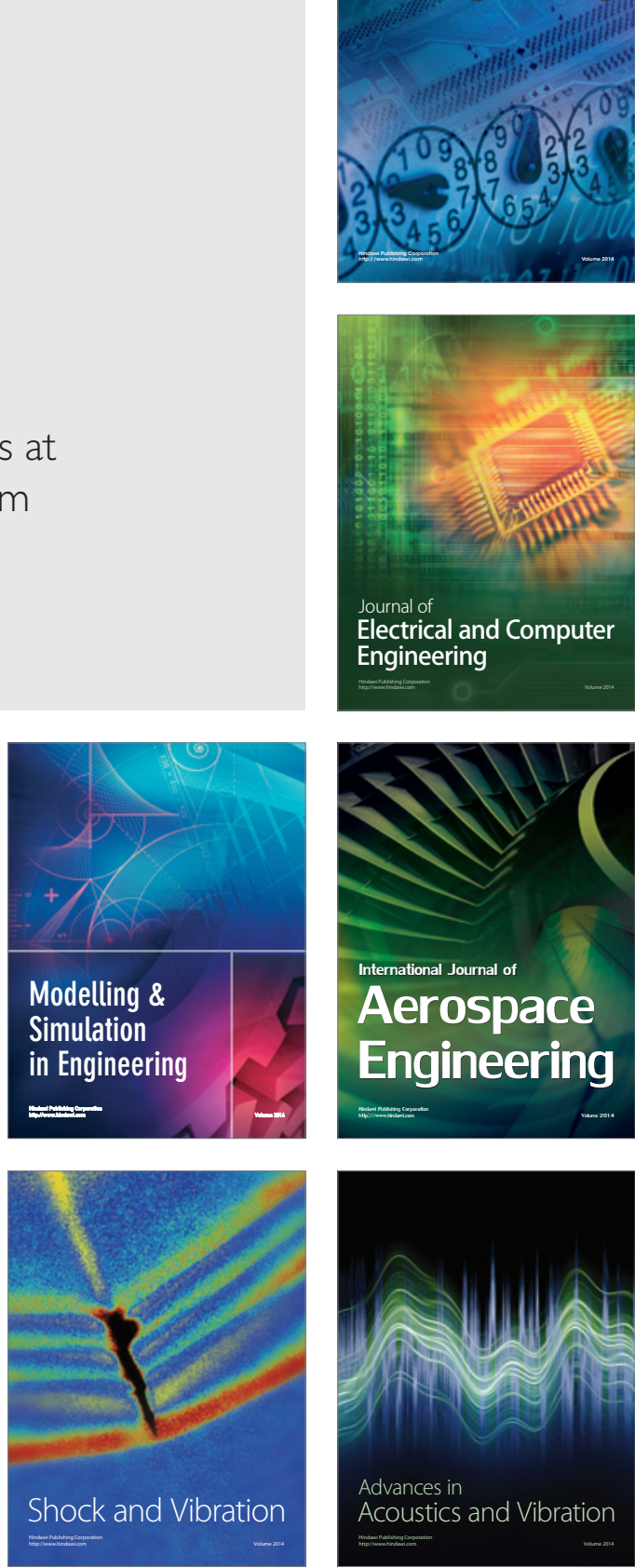